\title{
Influences of Weaving Parameters on Dynamic Characteristics and Stability Control of the Droplet Transfer in Arc-Weaving P-GMAW Process
}

\section{Di Wu}

School of Materials Science and Engineering, Shanghai Jiao Tong University, Shanghai 200240, PR China

\section{Yuxi Chen}

Shanghai Fanuc Robotics Co., Ltd., Shanghai 201206, PR China

\section{Huabin CHEN ( $\sim$ hbchen@sjtu.edu.cn )}

School of Materials Science and Engineering, Shanghai Jiao Tong University, Shanghai 200240, PR China https://orcid.org/0000-0002-0962-6232

\section{Shanben Chen}

School of Materials Science and Engineering, Shanghai Jiao Tong University, Shanghai 200240, PR China

\section{Research Article}

Keywords: Droplet transfer, P-GMAW, Weaving parameters, Arc and molten pool, Stability control

Posted Date: July 30th, 2021

DOl: https://doi.org/10.21203/rs.3.rs-747670/v1

License: (c) (i) This work is licensed under a Creative Commons Attribution 4.0 International License. Read Full License

Version of Record: A version of this preprint was published at The International Journal of Advanced Manufacturing Technology on January 14th, 2022. See the published version at https://doi.org/10.1007/s00170-021-08193-x. 


\title{
Influences of weaving parameters on dynamic characteristics and stability control of the droplet transfer in arc-weaving P-GMAW process
}

\author{
Di Wua ${ }^{\text {abb }}$, Yuxi Chen', Huabin Chen ${ }^{\mathrm{a}, *}$, Shanben Chen ${ }^{\mathrm{a}, *}$ \\ ${ }^{a}$ School of Materials Science and Engineering, Shanghai Jiao Tong University, Shanghai 200240, \\ PR China \\ ${ }^{b}$ Shanghai Collaborative Innovation Center of Laser Advanced Manufacturing Technology, \\ Shanghai University of Engineering Science, Shanghai 200240, China \\ ${ }^{c}$ Shanghai Fanuc Robotics Co., Ltd., Shanghai 201206, PR China
}

\begin{abstract}
:
The dynamic characteristics of droplet transfer is extremely complicated with the combined effects of gravity force and weaving motion during the weaving vertical-up welding on thick plate. In this paper, we firstly observed the droplet transfer behavior under various weaving parameters with high-speed photography and electrical signals during pulsed gas metal arc welding (P-GMAW). Then we investigated the influences of different weaving parameters on the arc shape and molten pool as well as droplet characteristics. By establishing a novel weaving-force model based on static-force balance theory (SFBT), we further revealed the drop transfer mechanism in weaving P-GMAW process. Extensive experimental results demonstrated that the suitable weaving parameters could effectively improve the droplet transfer stability and suppress welding defects including incomplete root penetration and lack of sidewall fusion. The findings of this paper will provide a basis for enhancing the welding process stability and obtaining a high-quality weld joint.
\end{abstract}

Keywords: Droplet transfer; P-GMAW; Weaving parameters; Arc and molten pool; Stability control

\footnotetext{
* Corresponding author:

Email address: hbchen@sjtu.edu.cn (Huabin Chen), sbchen@sjtu.edu.cn (Shanben Chen)
} 


\section{Introduction}

With a series of advantages including the high melting efficiency, high penetration force and enough flexibility, gas metal arc welding (GMAW) technique has been employed widely, especially in the welding production of large-scale thick plate of high-strength low-alloy (HSLA) steel [1]. As is well known, droplet transfer, namely the course of liquid metal transfer from the electrode tip to the workpiece can significantly impact the stability of the molten pool, the degree of weld penetration and spatter rate, thereby further affect the welding process stability and weld quality [2]. Hence, monitoring and control of the droplet transfer behavior in GMAW process are one means of obtaining a desired weld quality on thick plate.

In general, a spray transfer mode is desirable owing to the stability of the droplet transfer, low rates of spatter and deep bead penetration during the GMAW process, reported by Zhang et al. [3]. In continuous GMAW process, a stable spray transfer can be obtained in case of exceeding a critical current value. But the excessive heat input may easily produce some inevitable weld defects such as the exceptionally wide HAZ and welding deformation in weld joint, which can affect its micro-structure and mechanical properties [4]. Instead, P. Ghosh et al. [5, 6] revealed that a pulsed spray transfer can be achieved when the average current is less than critical current during the pulsed gas metal arc welding (P-GMAW) process. Nevertheless, it is difficult and time-consuming to determine the optimal pulsed parameters for obtaining a high-quality weld joint due to the larger number of controlling parameters. Moreover, the arc shape and metal droplet are constantly varying with a periodical change of welding current, and the droplet transfer has a direct relation with the process stability, weld bead formation and welding quality [7]. Therefore, the complicated dynamic characteristic of droplet transfer during P-GMAW process has been a difficult research problem in the fields of welding manufacturing for half a century.

Earlier studies by S. Subramaniam et al. [8] investigated the transitions from pulsed globular to spray to streaming transfer during P-GMAW process of 4047 aluminum workpiece and found that the droplet detachment, transfer mode, heat input or droplet size can be controlled by independently changing the pulse frequency and duty cycle. H. De Miranda et al. [9] developed an identification device for droplet detachments during pulsed GMAW and to assess the possibility of implementing a metal transfer control system, which was capable of setting parameters that provided stable transfer at one drop per pulse (ODPP) rate. Then P. Ghosh et.al [10] provides a physical realisation with basic understanding of the effects of hypothetical factor at various pulse parameters including the arc voltage on the characteristics of arc and behaviour of metal transfer in P-GMAW process. In addition, Wu et al. [11] conducted a high-power double-wire gas metal arc welding (GMAW) experiments with the single and double pulses technology to investigate the effects of single and double pulses on the metal transfer process and properties of the improved welding method.

From the above review, the former researchers almost focused on the droplet transfer behavior of flat-position GMAW process for thin plate and achieved a great progress in recent years. However, little attention has been devoted to the GMAW or P-GMAW process at other welding positions e.g. horizontal welding and vertical welding. Actually, the droplet transfer behavior is of importance in all-position welding. As reported by Chen et al. [12], the vertical-up welding is an important and frequently applied welding technique in practical welding production of large-scale thick-wall structure. Whereas some typical defects e.g. the incomplete penetration, lack of fusion and porosity may easily exist in the weld seam, which can seriously weaken the 
strength of welded structure. To overcome the adverse effect of the gravity and ensure a good weld appearance, it is necessary to apply an arc-weaving method for the P-GMAW process. Cai et al. [13] investigated the penetration of the bead for arc weaving vertical-up backing GMAW by experiments and numerical simulations, and applied a obtained a double compound angle groove for obtaining a better full penetration. In previous study, we developed a novel double-sided vertical P-GMAW with weaving on 50mm thick HSLA steel plate, and obtained a good weld joint without defects by analyzing the microstructure and mechanical properties of the weld seam [14].

However, the above study mainly investigated the effects of the welding parameters and weld groove mode on the weld appearance from the perspective of process analysis, there still exists the lack of deep understanding of the process characteristics of weaving vertical welding. Moreover, due to the combined effects of gravity and weaving motion, the droplet transfer behavior of weaving vertical welding is more complicated than that of the flat welding without weaving. In particular, different parameters including the weaving mode and weaving parameters could significantly affect the stability of the droplet transfer, and the difficulties in proper selection of weaving parameters also adversely affecting the weld appearance and weld quality. Hence, it is of great significance to investigate the dynamic characteristics of the droplet transfer for understanding the forming mechanism of weaving welding and avoiding the welding defects, which will provide a theory guidance for the application of weaving vertical-up welding.

In this study, the dynamic behavior of the droplet transfer during weaving P-GMAW with different weaving parameters were observed by using the synchronization acquisition system of high-speed images and electrical signals. The influences of the weaving parameters including weaving amplitude, frequency and dwell-time on the arc shape and droplet transfer were investigated, which further provides a basic understanding to analyse the primary mechanisms of weaving vertical P-GMAW process.

\section{Experimental procedure}

Fig. 1 illustrates the P-GMAW experimental system which consists of a FANUC six-axis welding robot, welding power source (LINCOLN i400), welding wire feeder (LINCOLN AutoDrive 4R90) and gas shielding device. To study the dynamic characteristics of droplet transfer, a high-speed video camera and electrical signal acquisition system were utilized synchronously. Combining with the auxiliary laser light (500W pulse power and 808nm wavelength), the high-speed video camera (FASTCAM SA-X2) with an infrared-visible optical filter is capable of suppressing the strong arc light, in order to capture the clear image of droplet and molten pool at 4000 frames per second. In addition, the current/voltage hall sensors and a DAQ card (NI USB-6212) were integrated in the Labview ${ }^{\circledR}$ platform to measure the welding current and voltage signals at a frame rate of $100-\mathrm{kHz}$. The electric signals were synchronized with the video frames to correlate the variations in welding current and arc voltage and with the formation and detachment of the droplets.

In this section, we conducted a series of vertical P-GMAW experiments on thick plate of HSLA steel (DILLIIMAX 690E) with dimensions of $500 \mathrm{~mm} \times 400 \mathrm{~mm} \times 25 \mathrm{~mm}$. The welding consumable is a YM-80A solid wire with a diameter of $1.2 \mathrm{~mm}$, using a mixture of $80 \% \mathrm{Ar}$ and $20 \%$ $\mathrm{CO}_{2}$ as shielding gas at a flow rate of $20 \mathrm{~L} / \mathrm{min}$. In order to discuss the effects of the weaving parameters on the droplet transfer behavior in this study, the other operational variables were kept constant for simplicity, as shown in Table 1. In addition, a butt-joint with the single-V $\left(45^{\circ}\right)$ symmetry groove root face of $1 \sim 2 \mathrm{~mm}$ and root gap of $2 \mathrm{~mm}$ was designed for obtaining a 
full-penetrated weld joint on thick plate, as depicted in Fig. 2.

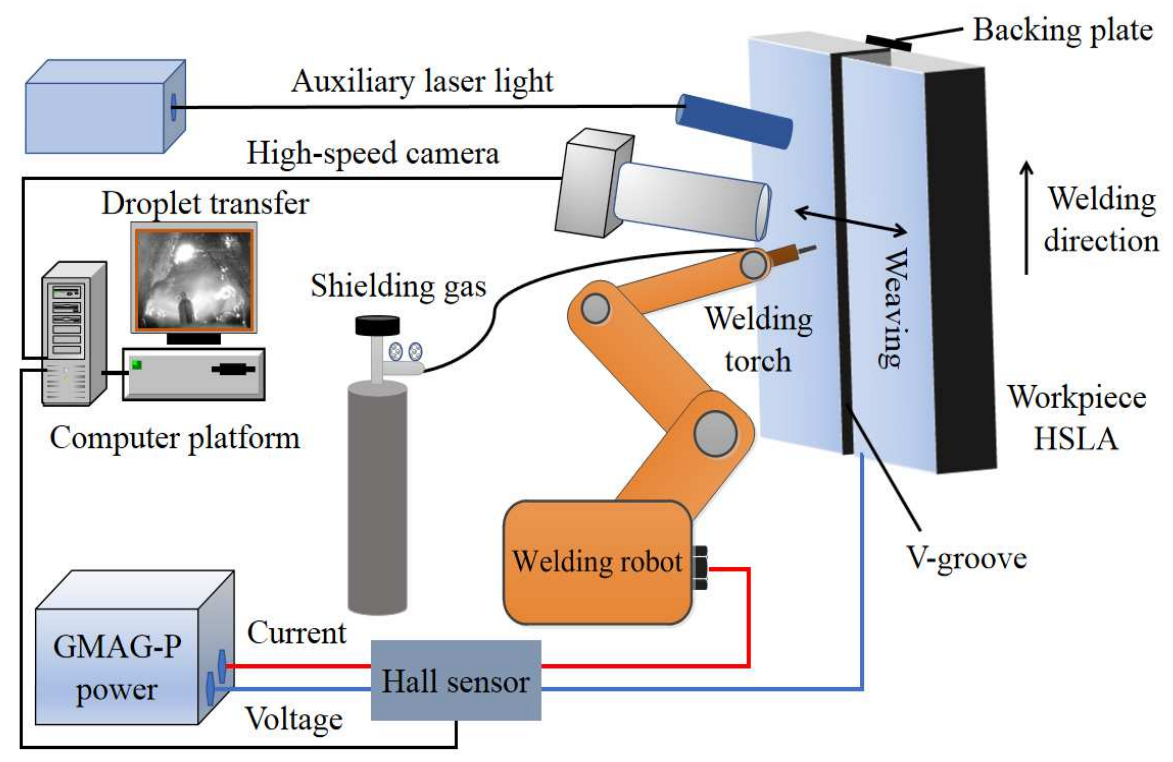

Fig. 1. Schematic of P-GMAW experimental system for observing the droplet transfer behavior.

Table 1. Detailed constant welding parameters

\begin{tabular}{cc}
\hline Parameters & Value \\
\hline Welding speed $/\left(\mathrm{cm} \cdot \mathrm{min}^{-1}\right)$ & 12 \\
Wire feed speed $/\left(\mathrm{cm} \cdot \mathrm{min}^{-1}\right)$ & 320 \\
Welding voltage/V & 26 \\
Peak current $/ \mathrm{A}$ & 446 \\
Background current/A & 48 \\
Pulse duration $/ \mathrm{ms}$ & 1.8 \\
Pulse off-time $/ \mathrm{ms}$ & 5.2 \\
Gas flow rate $/\left(\mathrm{L} \cdot \mathrm{min}^{-1}\right)$ & 20 \\
\hline
\end{tabular}

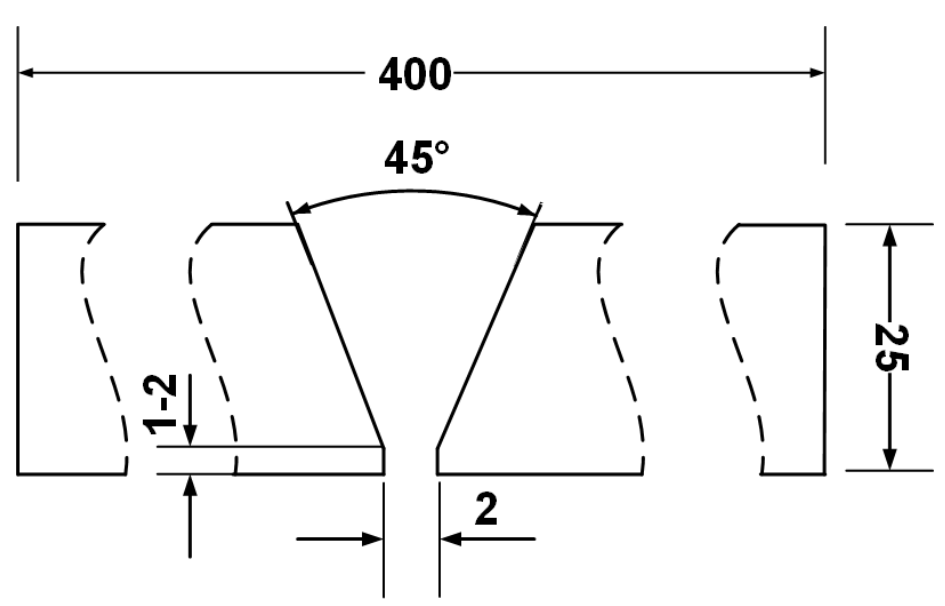

Fig. 2. Schematic of Single-V groove of vertical-up welding with weaving. 


\section{Characterization of droplet transfer behavior}

\subsection{Description of weaving parameters}

During vertical-up welding of thick plate, the gravity makes the liquid molten metal flow downward, which easily produce some weld defects e.g. undercut, welding slag and lack of fusion. To ensure a high-quality P-GMAW appearance, we applied a triangular weaving mode for welding robot and preseted a regular residence time on both sides of groove, as shown in Fig. 3. The welding torch inclination $(\alpha \leq \pi / 2)$ describes the angle between the electrode wire axis and the workpiece surface and arc-weaving amplitude $(d)$ is equal to half of the weaving width $(B), d=B / 2$. In addition, the weaving frequency of $\operatorname{arc}\left(f_{w}\right)$ depending on the weaving velocity $(v)$ and length $(A)$ is inversely proportional with the weaving period $(T)$. For simplicity, the weaving velocity was set as equal to the welding velocity, hence the weaving frequency $f_{w}=1 / T_{w}=A / v$.

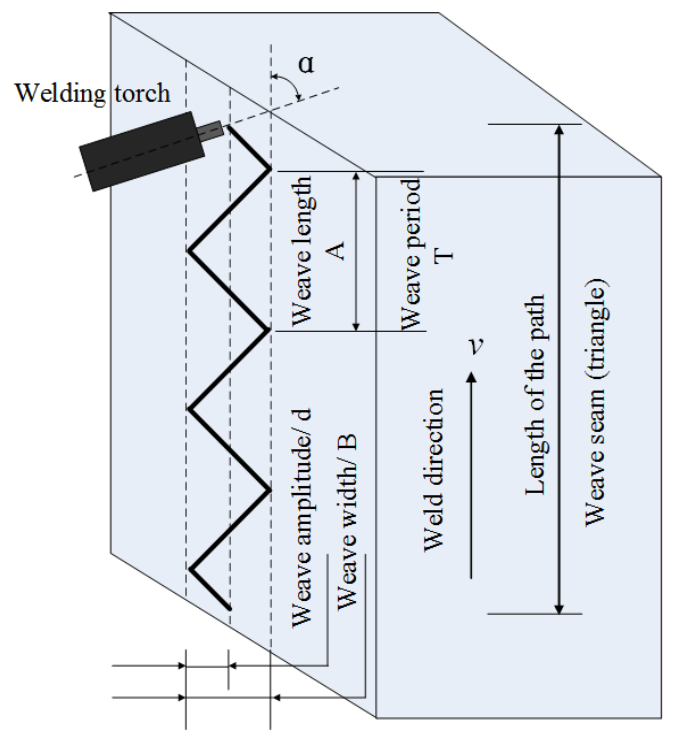

Fig. 3. Parameters definition in weaving vertical-up welding

\subsection{Diameter and impact location of droplets}

As mentioned, the size, impact location and transfer frequency of the droplet are important characteristic parameters, which have a significant effect on the welding stability. Ideally, the droplet diameter should be approximately equal to that of electrode wire, which leads to a stable welding process with minimal defects and spatters. To accurately obtain the droplet diameter under various welding conditions, we combined the high-speed image acquisition system with imaging processing technique to measure the diameter $(D)$ of each droplet on each frame. As shown in Fig. 4, taking the actual electrode wire as reference, the average diameter $(D)$ of droplet was calculated by the following expressions:

$$
D=\frac{D_{1}+D_{2}}{2} \times \frac{\phi}{C}
$$

where the diameters $\left(D_{1}\right.$ and $\left.D_{2}\right)$ in two directions of droplet were computed respectively on each frame of the video photographs. $\Phi$ denotes the actual wire diameter of $1.2 \mathrm{~mm}$, and $C$ is the measured pixel value in the image. Additionally, the impact location of droplet was defined as the distance $(L)$ between the impact position and the intersect of the workpiece surface and electrode wire. It can determine the fusion state of the groove root and sidewall, which as discussed in the following sections. To ensure the reliability and accuracy of characteristic parameters, we calculated the average values of the diameter and impact location over 20 droplets. 

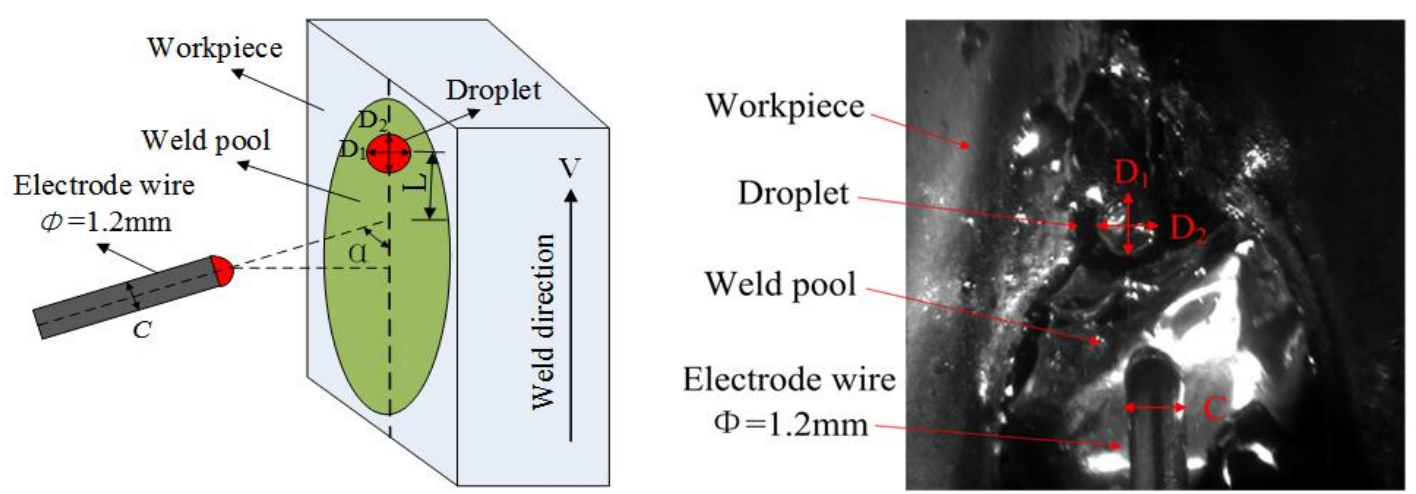

Fig. 4. Diameter and impacting location of a droplet in vertical-up welding.

\subsection{Droplet transfer frequency}

In order to obtain the droplet transfer frequency $\left(f_{D}\right)$ under differing welding parameters, we firstly acquired a series of images by adopting the high-speed image technology, and then performed a statistical analysis on the images corresponding to 100 droplets in each group of welding parameters. The interval between a pair of images was set as $0.25 \mathrm{~ms}$ according to 4000fps, and the average transfer frequency was calculated as:

$$
f_{D}=\frac{100}{0.00025 N}
$$

where $N$ is the amount of images corresponding to 100 droplets.

\section{Results and discussion}

\subsection{Dynamic characteristics of droplet transfer behavior}

On the basis of previous studies, the variation of welding torch inclination can directly affect the direction of arc forces. On the other hand, with the weaving of consumable electrode, the resultant arc acting on the groove periodically remains changing, which would cause certain influences to the droplet transfer. By combination of the droplet transfer images and current/voltage signals, we analyzed the welding process stability and droplet transfer characteristics, and further investigated the influences of different inclination angle and weaving parameters including the weaving frequency, amplitude and the dwell time on the droplet transfer. Table 2 lists the different experimental parameters, No.1 represents the welding test without weaving and No.2 No.9 represent the welding tests with weaving. Considering the incomplete root penetration and lack of sidewall fusion are two main welding defects easily occurred on thick plate, we will discuss the comparison results with different parameters on the groove root and sidewall in sections 4.1.1 4.1.5.

Table 2. Experimental parameters of P-GMAW process with and without weaving mode

\begin{tabular}{ccccc}
\hline No. & Torch angle $^{\circ}$ & Weaving frequency/Hz & Weaving amplitude $/ \mathrm{mm}$ & Dwell-time/s \\
\hline 1 & 85 & - & - & - \\
2 & 85 & 1.2 & 1.5 & 0.0 \\
3 & 45 & 1.2 & 1.5 & 0.5 \\
4 & 85 & 1.2 & 1.5 & 0.5 \\
5 & 85 & 1.2 & 0.5 & 0.5 \\
6 & 85 & 1.2 & 2.5 & 0.5 \\
7 & 85 & 0.6 & 1.5 & 0.5 \\
8 & 85 & 1.8 & 1.5 & 0.5 \\
9 & 85 & 1.2 & 1.5 & 1.0 \\
\hline
\end{tabular}




\subsubsection{Influence of weaving mode on droplet transfer}

Fig. 5 and Fig. 6 describe the droplet transfer process in vertical-up welding on thick plate without weaving (No.1) and with weaving (No.2) respectively, and the weaving frequency is $1.2 \mathrm{~Hz}$, the weaving amplitude is $1.5 \mathrm{~mm}$ and the dwell-time on both sidewalls is zero. Without weaving mode, the ignited arc center is coaxial to the electrode wire. Most of the droplets detaching from the electrode wire tip will impact on the front edge of the molten pool and a few droplets impact on the sidewall to form into the spatters. Through the statistical analysis, the average diameter $(1.28 \mathrm{~mm})$ of droplet is slightly larger than that of electrode wire, and the droplet transfer frequency is $210.5 \mathrm{~Hz}$ according to the droplet transfer duration (about $4.75 \mathrm{~ms}$ ). Specially, at the moments of $3.25 \mathrm{~ms}$ and $4.25 \mathrm{~ms}$ from Fig. 5, most of the large droplets impact outside of the irregular molten pool instead of the central region. Due to a larger temperature gradient near the molten pool edge and a faster cooling speed, the droplets solidify quickly after impacting into the weld pool, which can potentially affect the smoothness of the weld surface and produce the incomplete root penetration on thick plate.

Fig. 6(a) and Fig. 6(b) describe the droplet transfer at the groove root and sidewall with weaving mode, respectively. It can be seen that: (1) at the groove root, the arc length becomes larger with the weaving of the electrode wire; (2) at the groove sidewall, the arc shape changes with the hindering of sidewall. Statistical analysis shows that the droplet diameters in the groove root groove and groove sidewall are $1.08 \mathrm{~mm}$ and $1.12 \mathrm{~mm}$, and the droplet transfer frequencies of the groove root and sidewall are $444.4 \mathrm{~Hz}$ and $400 \mathrm{~Hz}$ corresponding to the transfer duration. Fig. 6 further indicates that with the weaving mode, the shape of molten pool is regular and the droplet transfer process is relatively stable. Moreover, the droplets on the groove root and sidewall can both impact into the center of weld pool without spatter, in order to ensure a full penetration at the groove root.

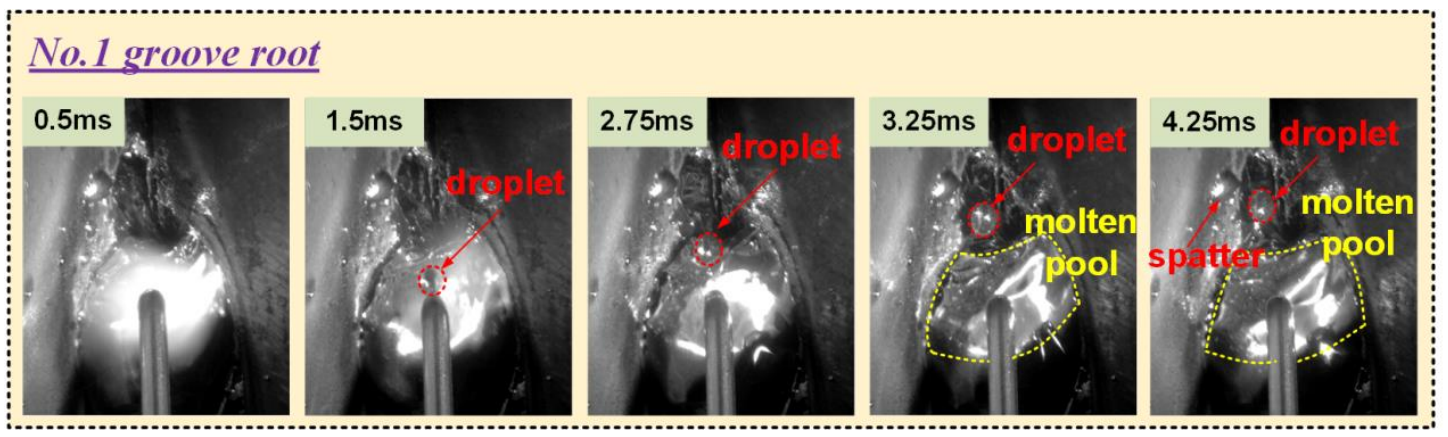

Fig. 5. Droplet transfer in P-GMAW process without weaving on groove root. 


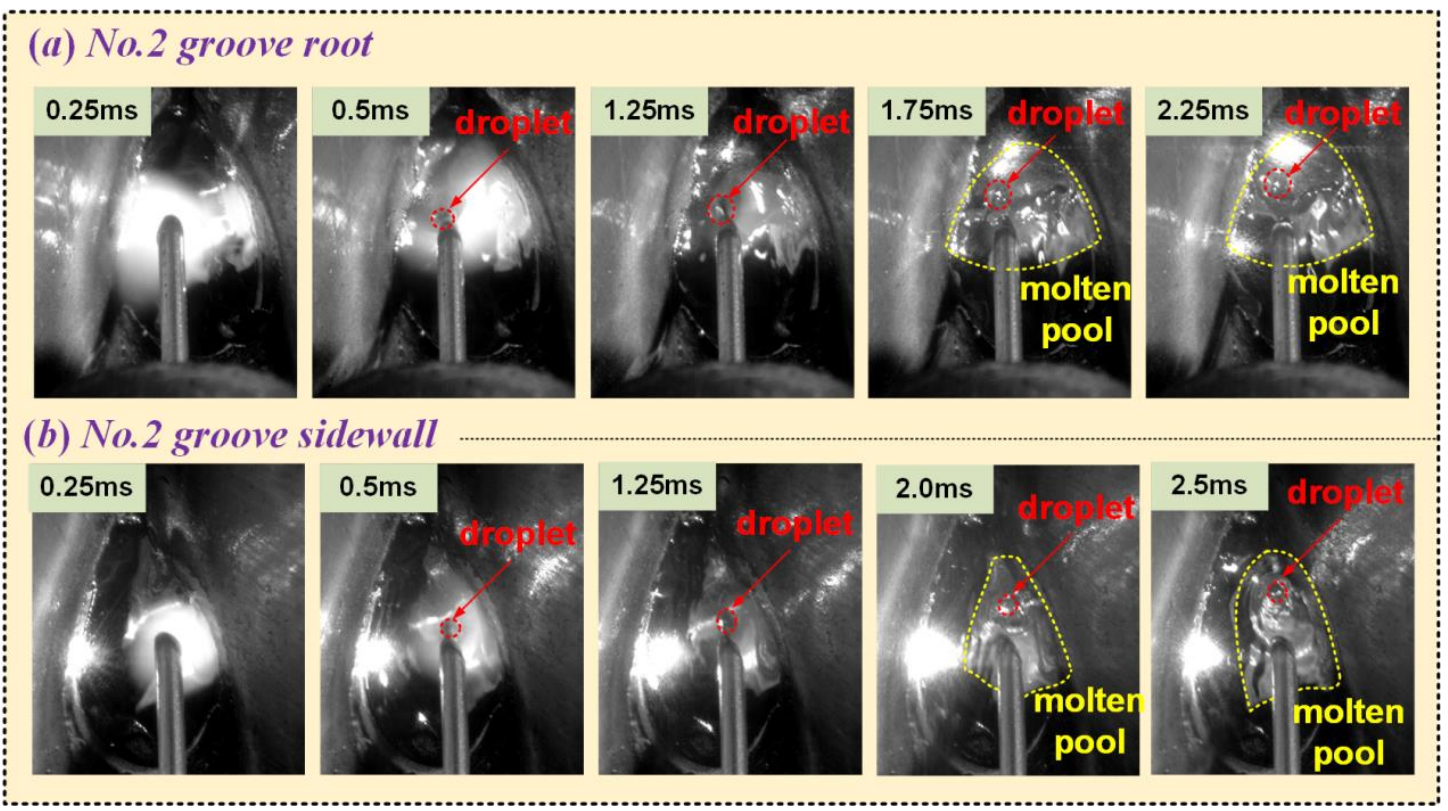

Fig. 6. Droplet transfer in P-GMAW process with weaving on (a) groove root (b) groove sidewall.

\subsubsection{Influence of weaving angle on droplet transfer}

To prevent the liquid metal from flowing downward and ensure the weld appearance in vertical-up welding, we adopted an obliquely upward welding method, namely the weaving inclination $\alpha \leq \pi / 2$. In this subsection, we observed and analyzed the droplet transfer behavior with different angles $(\alpha)$ to select a suitable inclination. Fig. 7 and Fig. 8 depict the droplet transfer process with the inclination angles of $45^{\circ}$ (No.3) and $85^{\circ}$ (No.4) on the groove root and sidewall respectively. The weaving frequency is $1.2 \mathrm{~Hz}$, the weaving amplitude is $1.5 \mathrm{~mm}$ and the dwell-time on both sidewalls is $0.5 \mathrm{~s}$. On the whole, the stability of molten pool with the angle of $85^{\circ}$ is significantly better than that of $45^{\circ}$. When the angle $\alpha$ is $45^{\circ}$, the droplet transfer modes of the root and the sidewalls are multiple droplets one pulse, the electrode wire tip presents a sharp "pencil shape" with a lager droplet transfer frequencies, as shown in Fig. 7(a). The droplet transfer frequencies in the root and sidewall are $444.4 \mathrm{~Hz}$ and $333.3 \mathrm{~Hz}$. When the angle $\alpha$ is $85^{\circ}$, despite the droplet transfer mode is also multiple droplets one pulse, the droplet transfer frequencies in the root $(250 \mathrm{~Hz})$ and sidewall $(235.3 \mathrm{~Hz})$ are both obviously lower than that $45^{\circ}$. Moreover, the droplet diameter at the angle of $85^{\circ}$ is approximately equal to the average diameter of the wire $(1.18 \mathrm{~mm})$, which can transfer the droplets into the weld pool smoothly.

When the angle $\alpha$ is set as $45^{\circ}$ as shown in Fig. 7, the shape of the molten pool is extremely irregular with the large spatters, and the special phenomenon of "double weld pools" even occur at the groove root (Fig. 7(a)), namely one of the weld pools forming after metal melting caused by the arc heating, another weld pool forming by the coalescence of liquid droplets with a significant amount of heat energy. Moreover, with a large temperature gradient at front edge of weld pool and a fast cooling speed, the two weld pools cannot connect together accompanied by the large spatters, which will seriously affect the seam appearance and weld quality. Instead, when the angle $\alpha$ is set as $85^{\circ}$ (seen in Fig. 8), the shape of the molten pool is regular and the droplet transfer process is relatively stable without splash, thus it can obtain a good weld appearance and high-quality weld joint. 


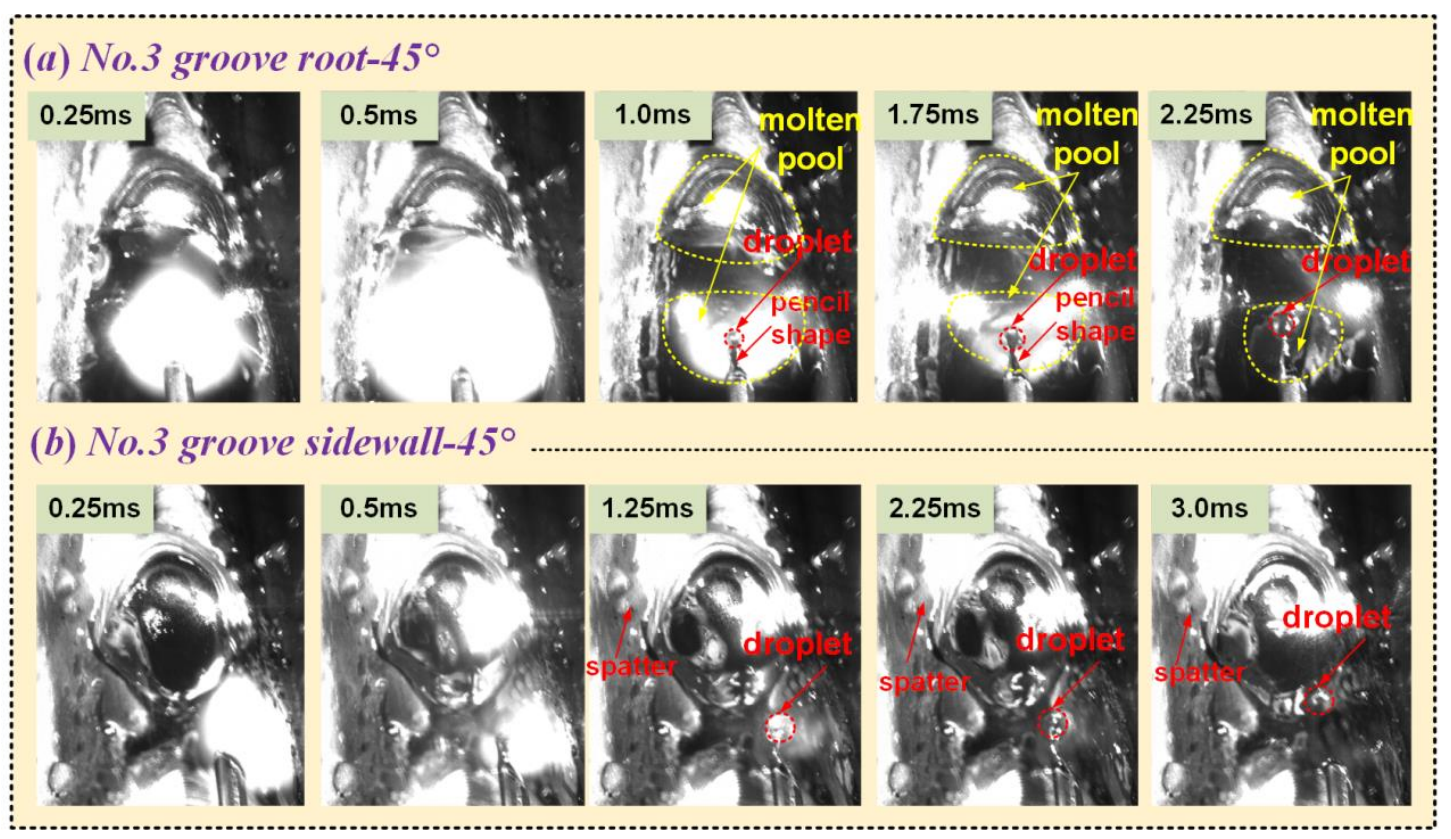

Fig. 7. Droplet transfer in weaving P-GMAW process with $\alpha=45^{\circ}$ on (a) groove root (b) sidewall.

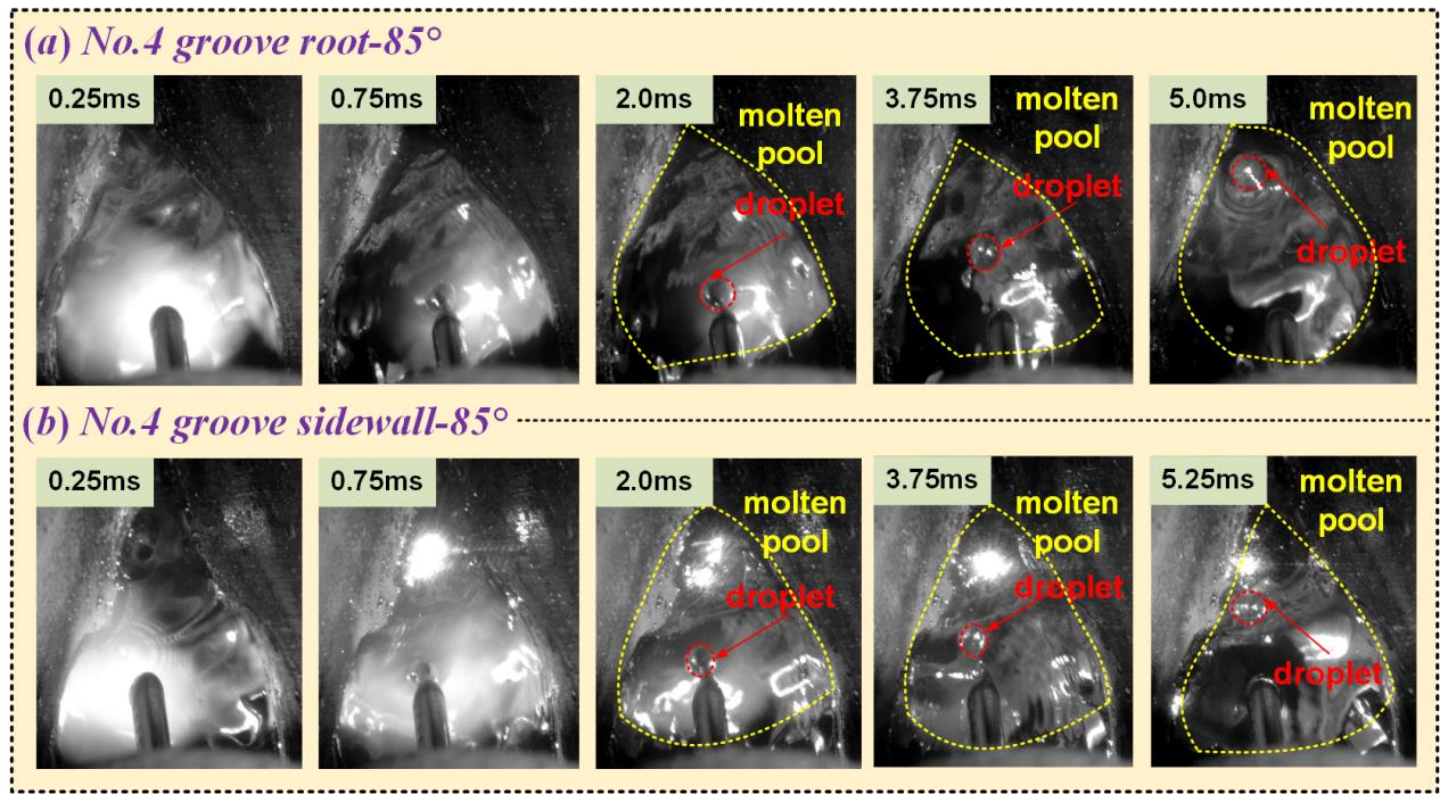

Fig. 8. Droplet transfer in weaving P-GMAW process with $\alpha=85^{\circ}$ on (a) groove root (b) sidewall.

\subsubsection{Influence of weaving amplitude on droplet transfer}

Fig. 8 Fig. 10 show the phenomena of droplet development and impingment of the droplet under different weaving amplitude of $1.5 \mathrm{~mm}$ (No.4), $0.5 \mathrm{~mm}$ (No.5) and $2.5 \mathrm{~mm}$ (No.6). The inclination angle is $85^{\circ}$, the weaving frequency is $1.2 \mathrm{~Hz}$, and the dwell-time on both sidewalls is 0.5s. As shown in Fig. 8 above, the droplet transfer mode is a typical projected transfer without large spatters. When the weaving amplitude decreases to $0.5 \mathrm{~mm}$, the change of arc-weaving is not obvious with large spatters on the groove sidewall. As similar to the welding without weaving (Fig.5), the detached droplets can easily impact outside of the molten pool, which will cause some welding defects e.g. the incomplete root penetration. Additionally, as the weaving amplitude increasing to $2.5 \mathrm{~mm}$, the arc-weaving tends to be more conspicuous and complicated. Under the arc weaving on the groove root, the contour of the molten pool presents a "pear shape" with narrow front-side and wide rear-side, as shown in Fig. 10. The detached droplets from the 
electrode wire tip accelerate in the arc plasma and coalesce to form the front-side pool, and then the droplets cool rapidly with a high temperature gradient, which may affect the root fusion. Under the arc weaving on the groove sidewall, due to the larger weaving amplitude, the weakened thermal effect of the arc could only generate the molten pool deviating from the sidewall instead of the entire weld seam, which easily produce the defects of incomplete fusion of root and slag inclusion in interlayer, as shown in Fig. 10(b).

With an increase of the weaving amplitude, the droplet transfer frequency decreases on the groove root while increases gradually on the groove sidewall, as shown in Fig. 11(a). The reason is that the arc thermal mainly acts on the groove root with a lower weaving amplitude. As the weaving amplitude increases, the thermal effect range becomes wider, which will make the heat input increase on the sidewall as well as the transfer frequency (seen in Fig. 11(a)). Fig. 11(b) also indicates that the weaving amplitude has little effect on the droplet diameter, and the average diameters $(1.18 \mathrm{~mm})$ of groove root and sidewall are almost equal to the wire diameter.

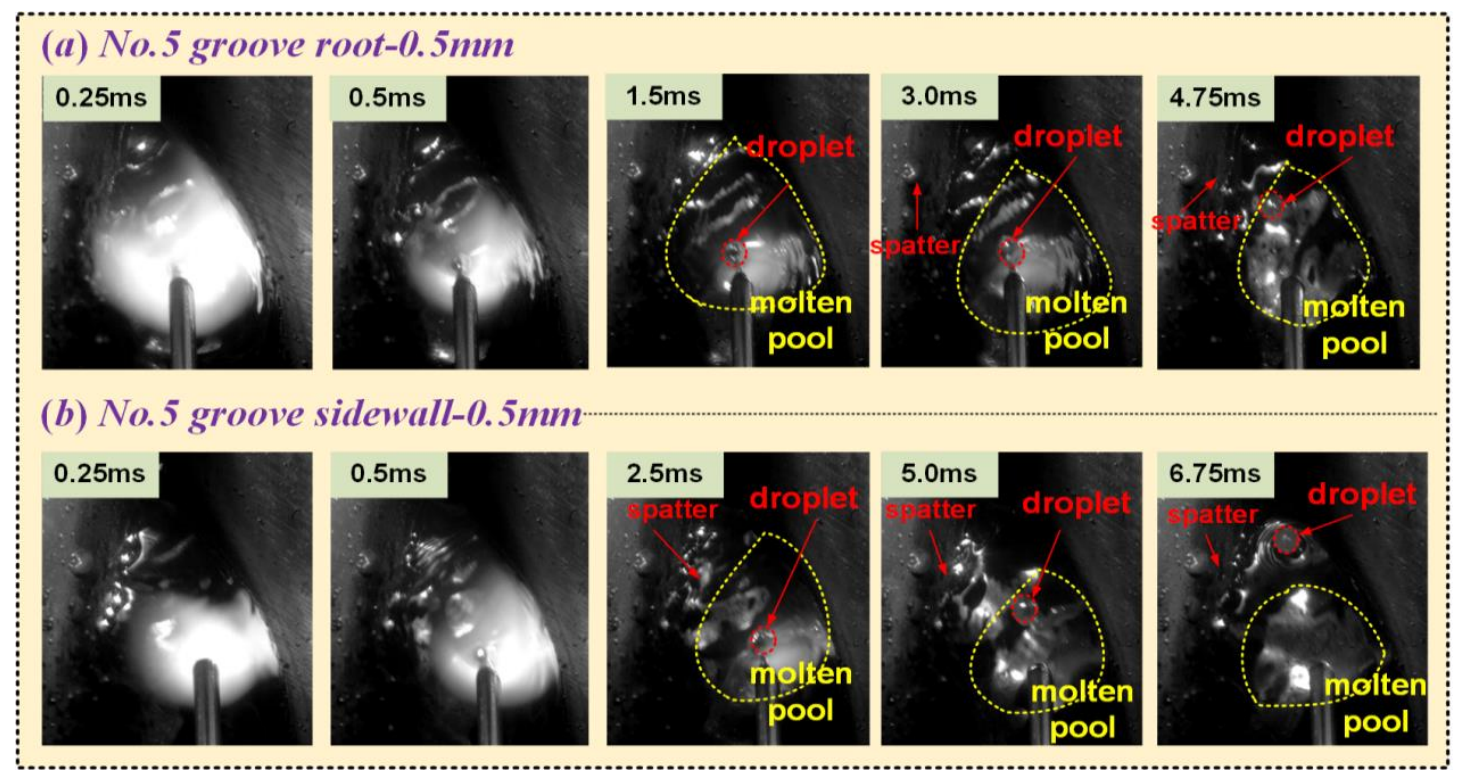

Fig. 9. Droplet transfer in weaving P-GMAW process with $\mathrm{d}=0.5 \mathrm{~mm}$ on (a) groove root (b) sidewall.

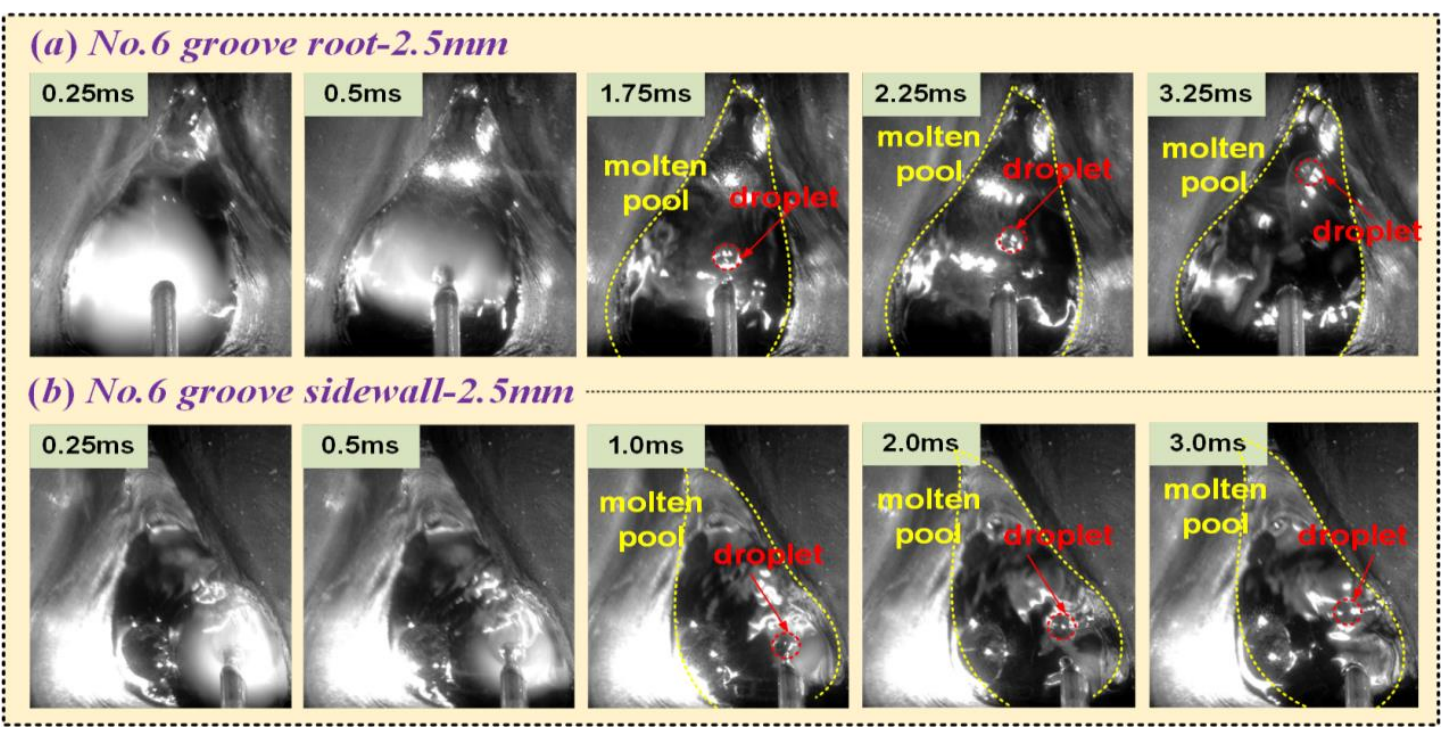

Fig. 10. Droplet transfer in weaving P-GMAW process with $\mathrm{d}=2.5 \mathrm{~mm}$ on (a) groove root (b) sidewall. 

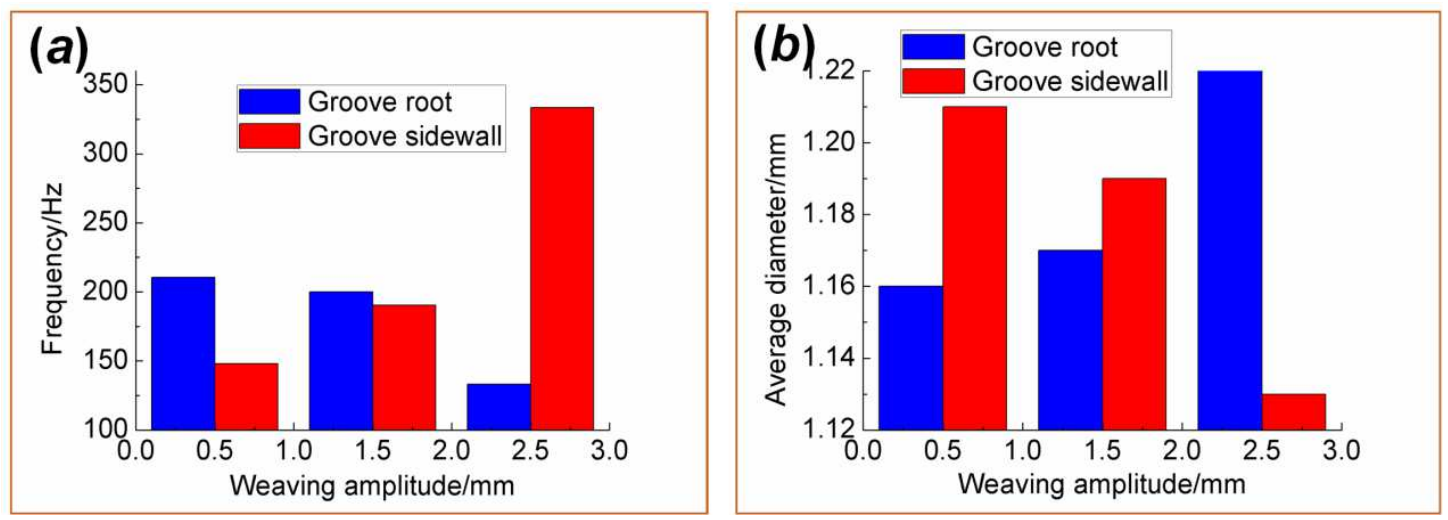

Fig. 11. Effects of weaving amplitude on (a) the frequency of droplet transfer (b) the average diameter of droplets.

Fig. 12 further describes the welding current and voltage signals under different weaving amplitude. The comparison results reveal that: (1) with a lower weaving amplitude $(0.5 \mathrm{~mm})$ or higher amplitude $(2.5 \mathrm{~mm})$, the welding current and voltage signals both appear a obvious fluctuation in the waveform. In particular, there exists some outliers (shown in red marks) denoting the welding process instability at some point, which could potentially produce some welding defects with large spatters; (2) On the contrary, when the weaving amplitude is $1.5 \mathrm{~mm}$, the fluctuation of the current and voltage signals are more smoothly, which indicates a more stable and continuous welding process with small spatter.

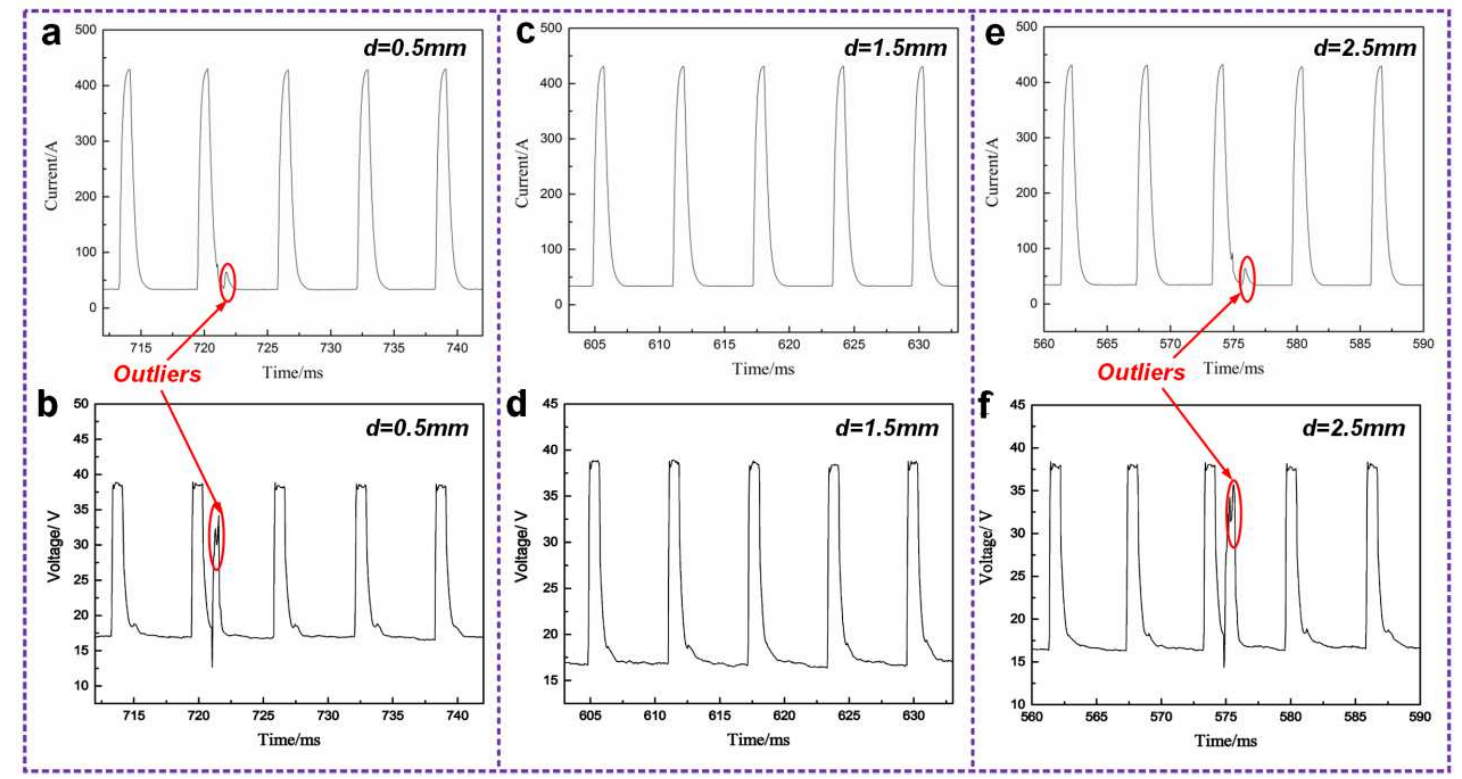

Fig. 12. Effects of weaving amplitude on the welding voltage and current (a) $d=0.5 \mathrm{~mm}$, current (b) $d=0.5 \mathrm{~mm}$, voltage (c) $d=1.5 \mathrm{~mm}$, current (d) $d=1.5 \mathrm{~mm}$, voltage (e) $d=2.5 \mathrm{~mm}$, current (f) $d=2.5 \mathrm{~mm}$, voltage.

\subsubsection{Influence of weaving frequency on droplet transfer}

Fig. 13 and Fig. 14 present the droplet transfer process with the different weaving frequency of $0.6 \mathrm{~Hz}$ (No.7) and $1.8 \mathrm{~Hz}$ (No.8). The inclination angle is $85^{\circ}$, the weaving amplitude is $1.5 \mathrm{~mm}$, and the dwell-time on both sidewalls are $0.5 \mathrm{~s}$. The droplet transfer process with the weaving frequency of $1.2 \mathrm{~Hz}$ (seen in Fig. 8) is previously described. Through comparing with different weaving frequency, the droplet transfer process with $0.6 \mathrm{~Hz}$ is less stable than $1.2 \mathrm{~Hz}$. Moreover, the impact location of droplet is inclined to the front-side of molten pool, and the molten pool presents a "pear shape" with a few spatters. In addition, when the weaving frequency increases to 
$1.8 \mathrm{~Hz}$, the droplet transfer process becomes extremely unstable. Because of a larger weaving frequency and shorter weaving period, the droplet transfer mode is a typical spray transfer with arc heat concentration and the large spatters, which have important influence on the final weld appearance and weld quality.

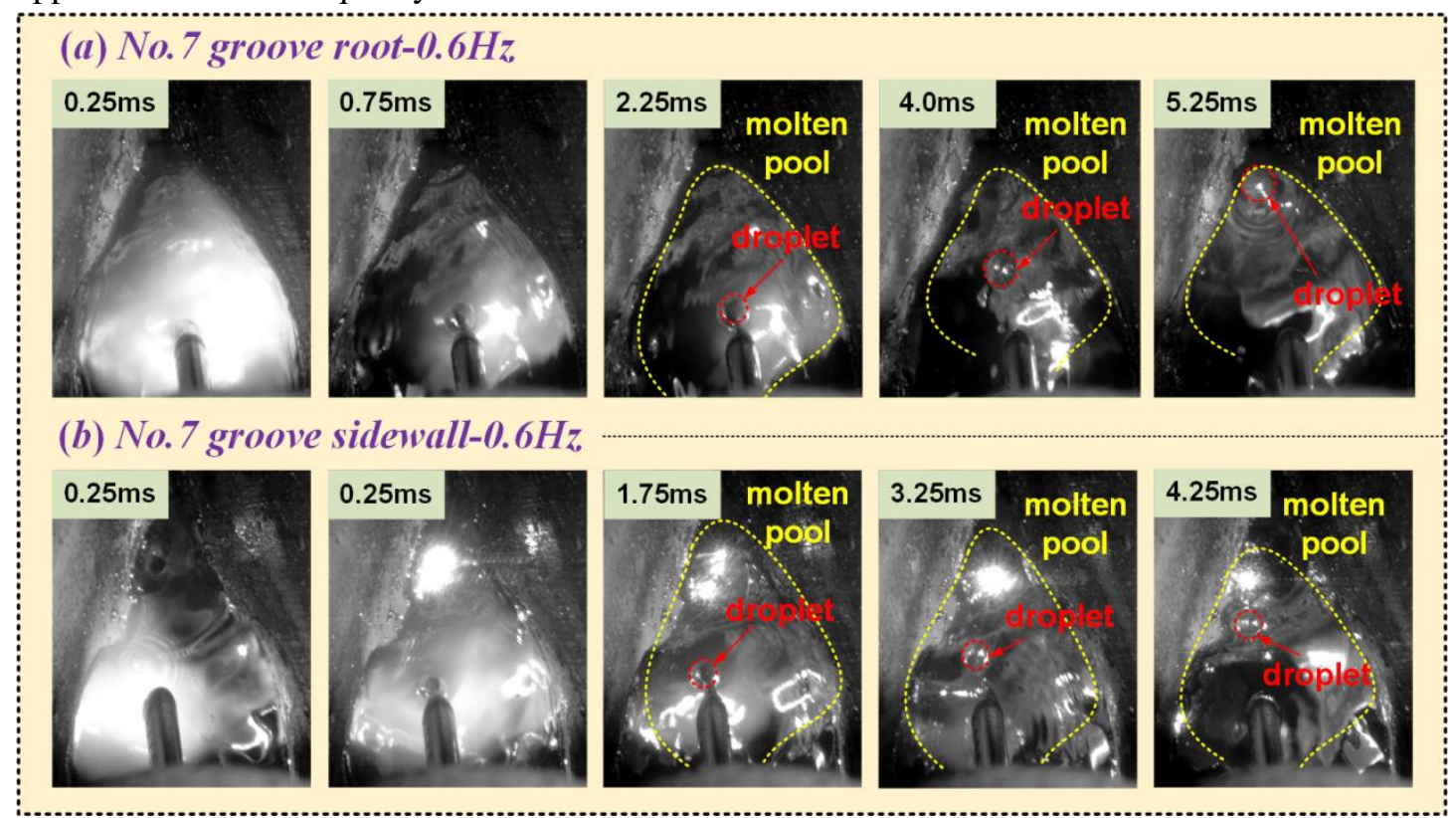

Fig. 13. Droplet transfer in weaving P-GMAW process with $f_{w}=0.6 \mathrm{~Hz}$ on (a) groove root (b) sidewall.

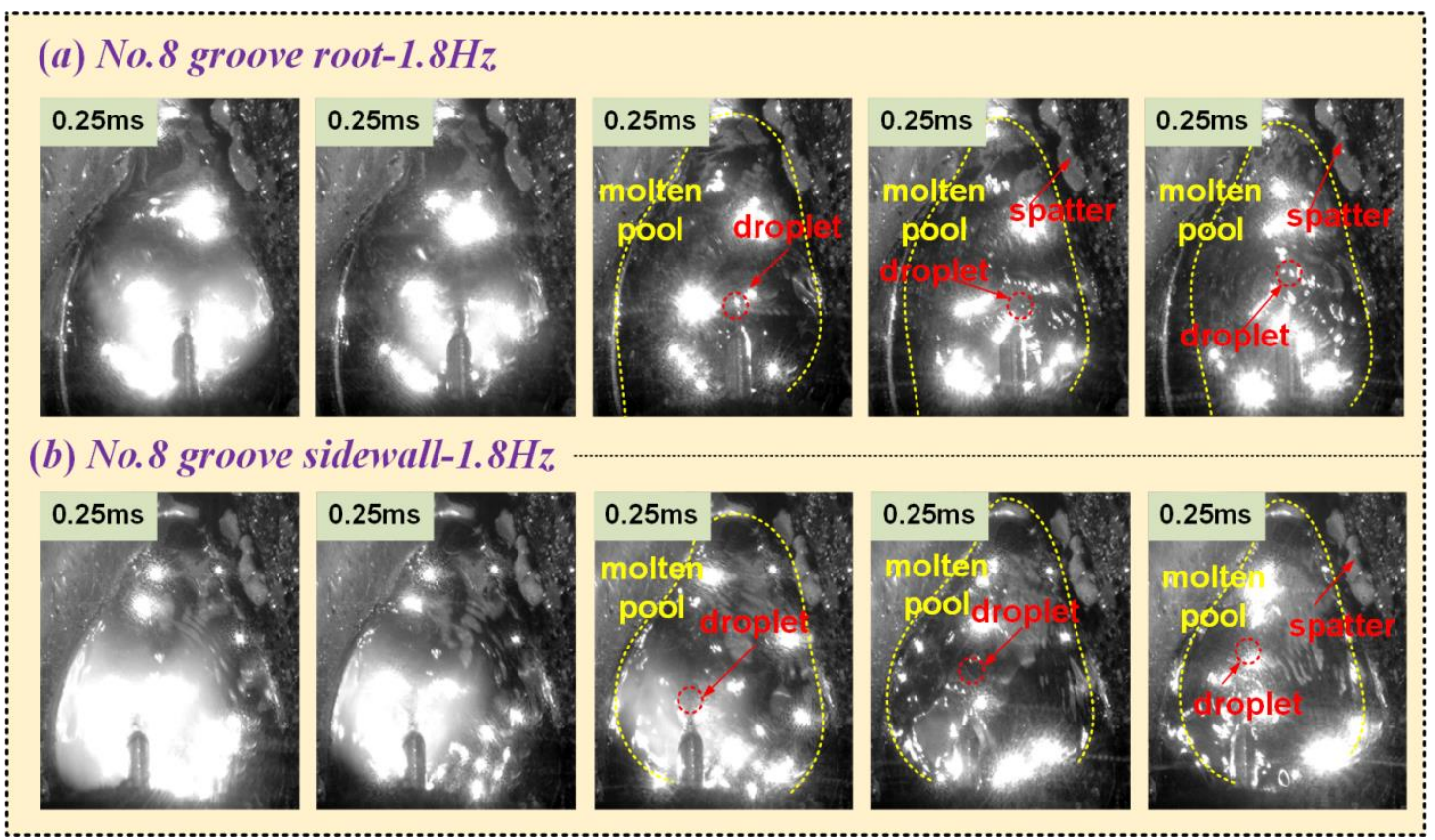

Fig. 14. Droplet transfer in weaving P-GMAW process with $f_{w}=1.8 \mathrm{~Hz}$ on (a) groove root (b) sidewall.

As shown in Fig. 15(a), when the weaving frequency increases from $0.6 \mathrm{~Hz}$ to $1.2 \mathrm{~Hz}$, the droplet transfer frequency on the groove root and sidewall both increase slightly and the average droplet diameters are close to the electrode wire diameter. This is because the lower weaving frequency makes a longer period of oscillation that allow the weaving arc to move along the welding direction and the welding heat is dispersed in the larger arc acting area per unit time, the droplet transfer frequency will become lower. Instead, when the weaving frequency increasing to $1.8 \mathrm{~Hz}$, the transfer frequency increased significantly owing to a shorter period of oscillation and more 
concentrated arc heat. In addition, as shown in Fig. 15(b), the average diameters of the weaving frequency at $0.6 \mathrm{~Hz}$ and $1.2 \mathrm{~Hz}$ show little difference which are equal to the diameter of the electrode wire $(1.18 \mathrm{~mm})$. With the increasing of the weaving frequency $(1.8 \mathrm{~Hz})$, the average diameters of the groove root and sidewall decrease obviously, thereinto the diameters of the groove root and sidewall are $0.98 \mathrm{~mm}$ and $0.92 \mathrm{~mm}$, respectively.
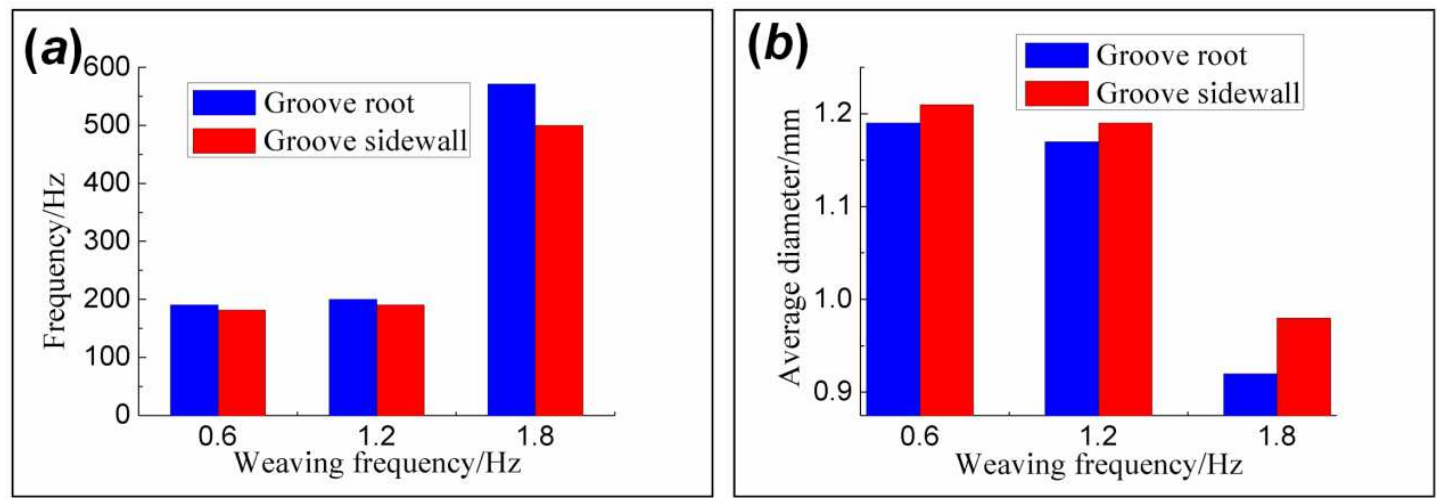

Fig. 15. Effect of weaving frequency on (a) the frequency of droplet transfer (b) the average diameter of droplets.

Fig. 16 shows the effects of weaving frequency on the welding current and voltage signals. When the weaving frequency are $0.6 \mathrm{~Hz}$ (a) and $1.8 \mathrm{~Hz}(\mathrm{~b})$, the acquired current and voltage signals both fluctuate greatly with some obvious outliers on the groove root and sidewall. Specially, with the weaving frequency of $0.6 \mathrm{~Hz}$, the impacting location of the droplet points to the front-side of the molten pool, which could cause the large welding spatters; while with weaving frequency of $1.8 \mathrm{~Hz}$, the times of short-circuits increase significantly and the welding process is extremely unstable. This is because that a larger weaving frequency can generate excessive concentrated arc heat, which will significantly promote the wire melting and increase the droplet transfer frequency. Instead, when the weaving frequency is set as $1.2 \mathrm{~Hz}$, the welding current and voltage signals tend to be balanceable and homogeneous, which can obtain a more stable welding process and a good weld formation quality.

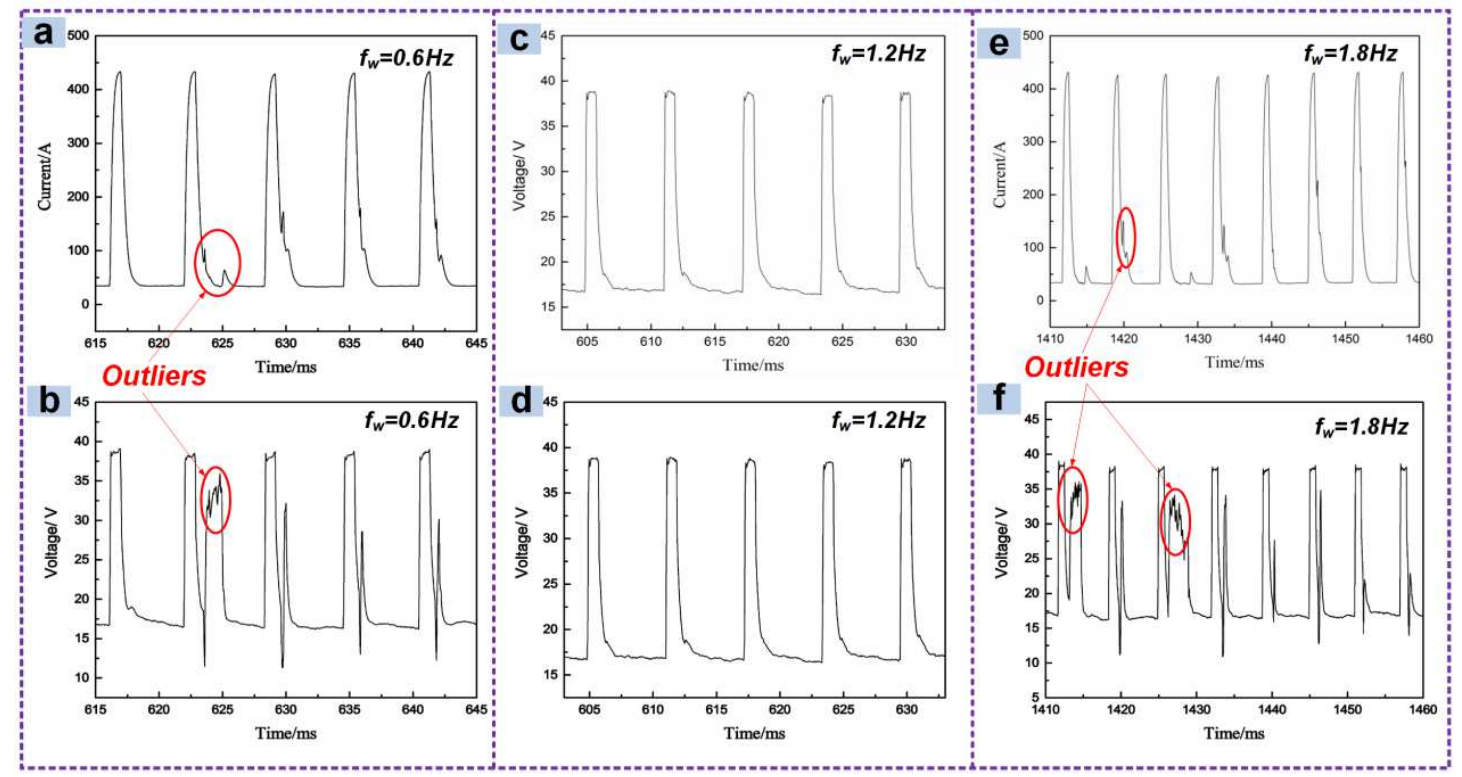

Fig. 16. Effect of weaving frequency on the welding voltage and current (a) $f_{w}=0.6 \mathrm{~Hz}$, current (b) $f_{w}=0.6 \mathrm{~Hz}$, voltage (c) $f_{w}=1.2 \mathrm{~Hz}$, current (d) $f_{w}=1.2 \mathrm{~Hz}$, voltage (e) $f_{w}=1.8 \mathrm{~Hz}$, current (f) $f_{w}=1.8 \mathrm{~Hz}$, voltage. 


\subsubsection{Influence of dwell-time on droplet transfer}

In the practical groove welding on thick HSLA steel plate, the incomplete sidewall fusion should be avoided to obtain a good weld formation. Considering the arc dwell time on sidewall directly reflects the arc heating acting on the sidewall, which can affect the fusion states of the groove sidewall. Therefore, it is necessary to investigate the effects of different dwell time on the droplet transfer behavior. Fig. 17 presents the dynamic behavior of the droplet transfer on the groove root and sidewall with the dwell time (1.0s). Compared to the previous results with different dwell time 0s (Fig. 6) and 0.5s (Fig.8), it is found that the dwell time mainly influences the droplet transfer of the groove sidewall instead of groove root. The reason is that the droplet transfer modes of the groove root are all the spray transfer with the different dwell time, which only affects the frequency and the diameter of the droplet. However, the effects of different dwell time on the droplet transfer of the groove sidewall are more significant and complicated. When the dwell time are set as $0 \mathrm{~s}$ and $0.5 \mathrm{~s}$, the detached droplets could impact into the molten pool without the large spatters, and the droplet transfer process is relatively stable.

Upon further analysis for the comparison results, the fewer molten metal on the sidewall without dwell time easily generates the defect of incomplete fusion, while the dwell time of $0.5 \mathrm{~s}$ can obtain a better sidewall fusion. When the dwell time continues to increase to $1.0 \mathrm{~s}$, as shown in Fig. 17, with the longer dwell time, the larger heat input on the sidewall can melt more metal, which is beneficial for avoiding the incomplete sidewall fusion. However, due to the excessive dwell time, too heavily concentrated arc heat could rapidly increase the melting rate of the electrode wire and the frequency of the droplet transfer, which will lead to the instability of the droplet transfer process. It can be seen that not all of the droplets impact into the molten pool, and part of the droplets fall into the sidewall in the form of spatter, which can easily increase the the probability of the slag inclusion and porosity in welding joint.

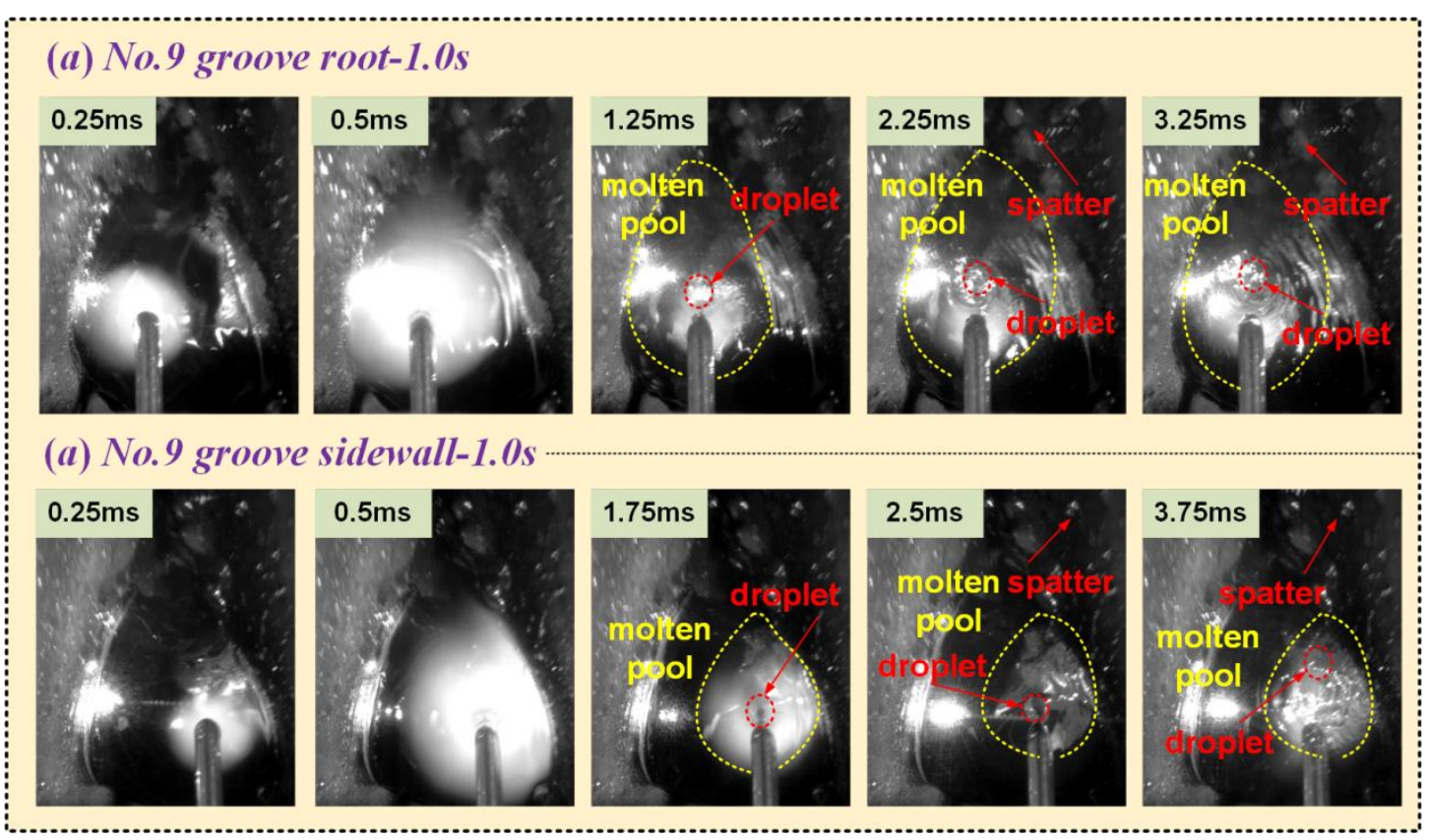

Fig. 17. Droplet transfer in weaving P-GMAW process with $\mathrm{t}=1.0 \mathrm{~s}$ on (a) groove root (b) sidewall.

Fig. 18 presents the effect of the dwell time on the droplet transfer frequency, we can see that with the increasing of the dwell time, the droplet frequency of the groove root and sidewall both decrease and then increase. When the dwell time is $1.0 \mathrm{~s}$, the droplet frequency of the groove root 
and sidewall can reach the maximum values of $571.4 \mathrm{~Hz}$ and $571.6 \mathrm{~Hz}$. In addition, as shown in Fig. 15(b), the average diameters of the groove root and sidewall are almost the same, which are slightly less than the diameter of the electrode wire.
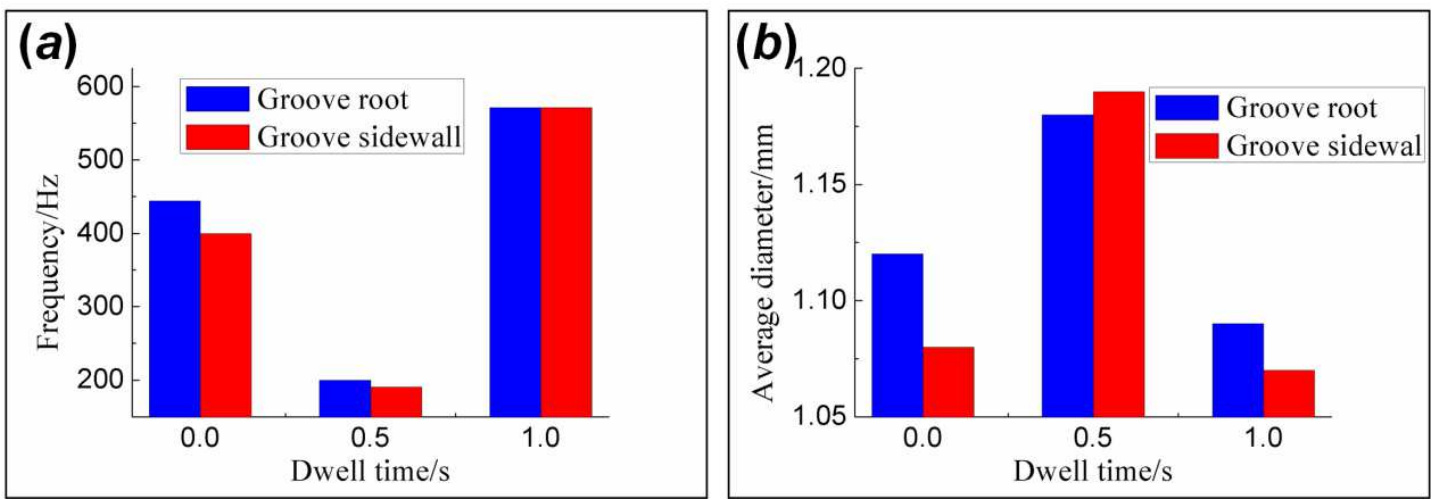

Fig. 18. Effect of dwell time on (a) the frequency of droplet transfer (b) the average diameter of droplets.

Fig. 19 further shows the effect of dwell-time on the welding voltage and current signals. It can be seen that when $\mathrm{t}$ is set as $0 \mathrm{~s}$ or $1.0 \mathrm{~s}$, the voltage and current signals fluctuated violently with some obvious outliers, which will affect the magnitude and direction of the electromagnetic force acting on the droplet inevitably and disrupt the stability of droplet transfer process. When the dwell-time is equal to $0.5 \mathrm{~s}$, the process is most stable without the outliers.
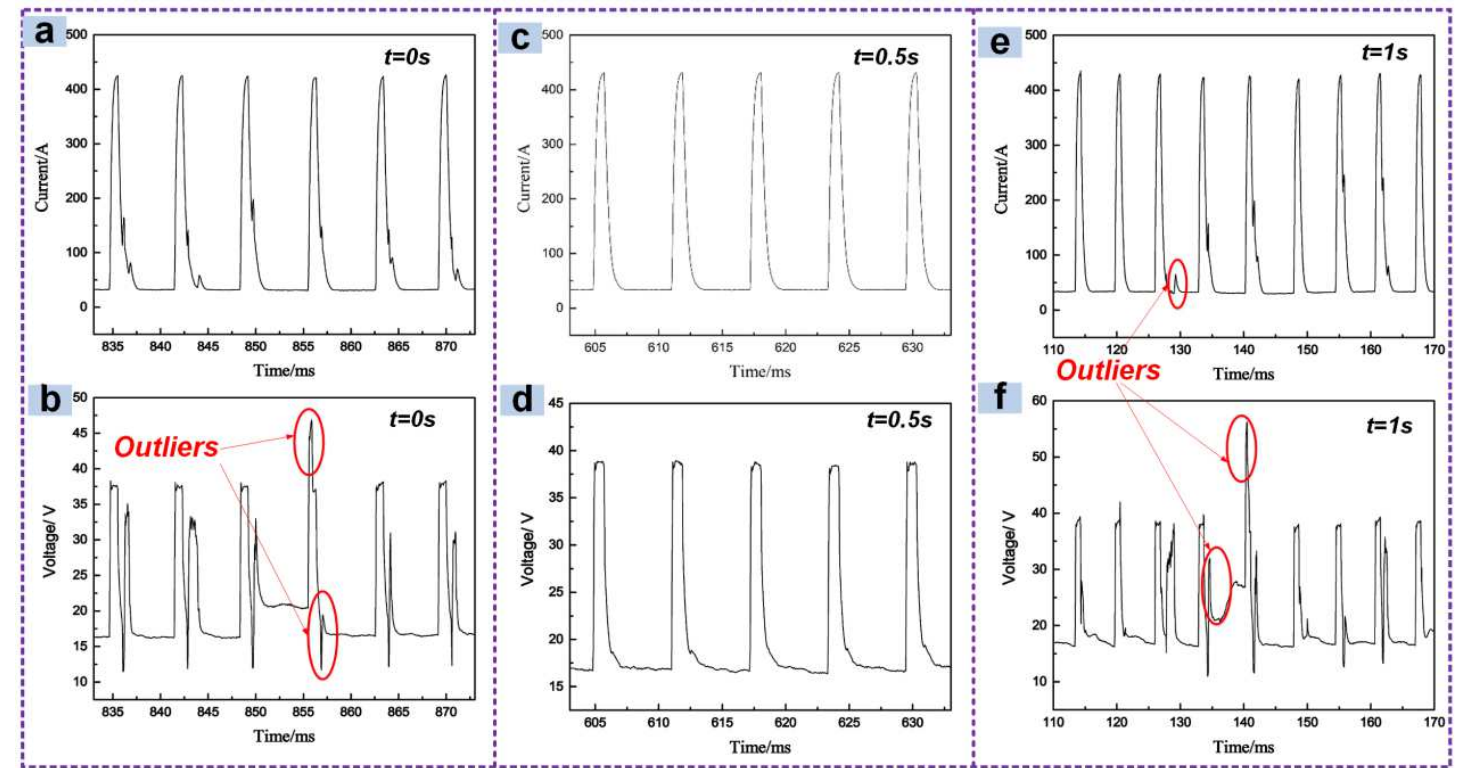

Fig. 19. Effects of dwell time on the welding voltage and current (a) $t=0 \mathrm{~s}$, current (b) $t=0 \mathrm{~s}$, voltage (c) $t=0.5 \mathrm{~s}$, current (d) $t=0.5 \mathrm{~s}$, voltage (e) $t=1 \mathrm{~s}$, current (f) $t=1 \mathrm{~s}$, voltage.

\subsection{Development of weaving-force model for droplet transfer}

During the vertical-up weaving P-GMAW process, the filler-metal droplets mainly depends upon the magnitudes and orientations of the various forces acting on the droplet. Fig. 20 illustrates a novel weaving-force model consisting of different forces acting on the droplet in vertical-up welding. In contrast to the welding without arc weaving, except for the gravitational force $\left(F_{g}\right)$, surface tension $\left(F_{r}\right)$, plasma drag force $\left(F_{p}\right)$ and electromagnetic force $\left(F_{e}\right)$, there exists a weaving inertial force $\left(F_{i}\right)$ in the weaving welding which can describe the weaving performance on the droplet behavior. In particular, this weaving-force model differs from those conventional force 
models used by previous authors in incorporating the effect of the weaving motion. In the following, we will systematic investigate the influences of these forces on the droplet development and impingement on the molten pool.

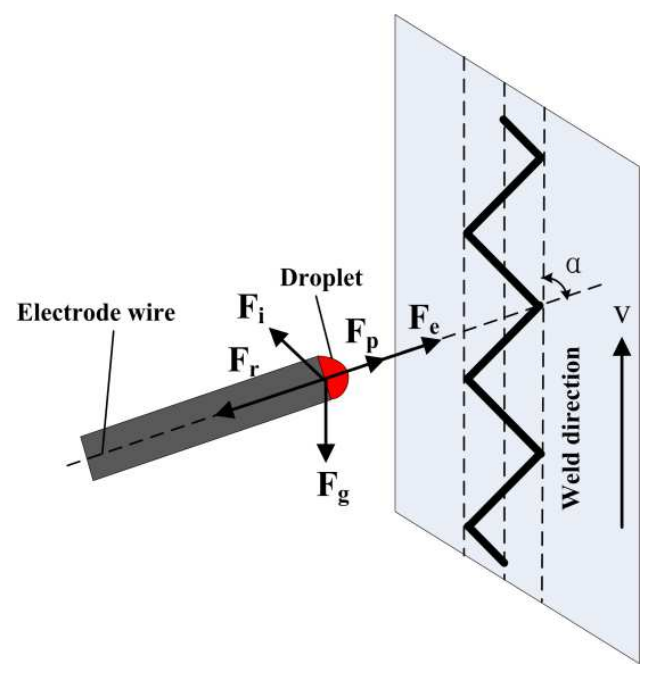

Fig. 20. The distributions of forces affecting droplet transfer in vertical-up welding.

In the vertical-position welding, the gravity is the force hindering the droplet transfer, which can be calculated by the following expression:

$$
F_{g}=\frac{4}{3} \pi R^{3} \rho_{d} g
$$

where $R$ is the droplet radius, $\rho_{d}$ is the density of the droplet, and $g$ is the gravitation constant. The droplet density $\rho_{d}$ remains unchanged when the welding consumable is selected. Hence, the droplet gravity is only relevant to the droplet radius.

Surface tension is main force impeding the liquid droplet detach from the electrode wire tip, which significantly affect the droplet transfer behavior, it can be expressed as:

$$
F_{r}=2 \pi R \sigma
$$

where, the surface tension coefficient $\sigma$ is mainly determined by the material composition, environment temperature and the shielding gas e.t. In our welding experiments, the surface tension coefficient is a constant. Thus, surface tension acting on the droplet just depends on the droplet radius, which indicates the surface tension is directly proportional to the droplet radius.

The plasma drag force is an arc thrust generated by the plasma drag acting on the droplet, which can obviously promote the droplet transfer. For the force acting on the spherical droplet in the plasma flow with the uniform velocity, which is given by

$$
F_{p}=\frac{C_{D} A_{p} \rho_{f} v_{f}^{2}}{2}
$$

where $C_{D}$ is the drag coefficient of plasma. $A_{p}$ is the effective area of the plasma acting on the droplet surface, which depend on the droplet radius. $\rho_{f}$ and $v_{f}$ are the density and velocity of the plasma which associate with the welding current. According to formula (5), the plasma drag force will increase with the increasing of the droplet radius and welding current.

Additionally, the electromagnetic force is the key factor in affecting the droplet detachment [15]. The electromagnetic force is mainly caused by the Lorentz magnetic force acting on the 
current inside the droplet. According to Lorentz Law, the electromagnetic force $\left(F_{e}\right)$ can be expressed as follows:

$$
F_{e}=\stackrel{\mathbf{u}}{J} \times \stackrel{\mathbf{u}}{B}
$$

Assuming that the current density uniformly distribute within the droplet, then we can obtain the total electromagnetic force by the integral of droplet surface according to (6):

$$
\begin{gathered}
F_{e}=\frac{\mu_{0} I^{2}}{4 \pi} F_{z} \\
F_{z}=\ln \frac{R \sin \theta}{r}-\frac{1}{4}-\frac{1}{1-\cos \theta}+\frac{2}{(1-\cos \theta)^{2}} \ln \frac{2}{1+\cos \theta}
\end{gathered}
$$

where $\mu_{0}$ is the magnetic permeability, $\theta$ is the arc conduction angle. According to formula (7) and (8), the electromagnetic force $F_{e}$ is the function of the arc shape coefficient $F_{z}$ which can be determined by the conduction angle $\theta$ [16]. Fig. 21 presents the corresponding relationship between the conduction angle $\theta$ and the arc shape coefficient $F_{z}$. When the conductive area is small with a shallower angle, the arc is in shrinkage condition which can hinder the droplet transfer. The arc shape coefficient $F_{z}$ and the electromagnetic force $F_{e}$ are both negative. However, with the increasing of the conductive area, the arc shape is changing with the transition from the contraction state to dispersing state. Then the arc conduction angle $\theta$ becomes larger with the negative arc shape coefficient $F_{z}$ and electromagnetic force $F_{e}$, which will promote the droplet transfer finally. In summary, the distribution of electric current and the arc shape can directly determine the the magnitude and direction of the electromagnetic force.

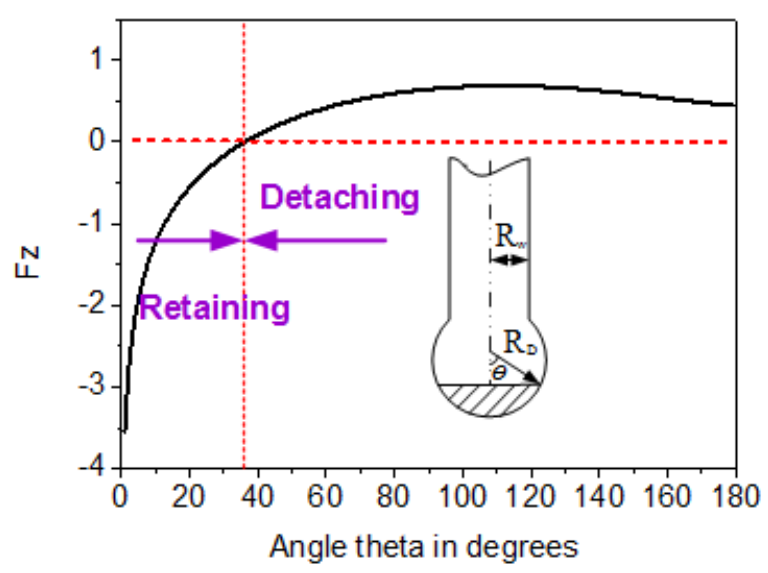

Fig. 21. Variation of shape coefficient as a function of conduction zone angle.

During the vertical welding with weaving mode, the welding torch weaves from side to side along with the welding direction, thus generating a so-called weaving inertia force which could promote the droplet detaching from the electrode wire and increase the droplet transfer frequency. According to equation (9), the inertial force $F_{i}$ is related to the droplet mass, weaving frequency and weaving amplitude, which can be expressed as:

$$
F_{i}=\frac{m f_{w}^{2} d}{\sin \alpha}
$$

where $m$ is the droplet mass, $f_{w}$ is the weaving frequency, $d$ is the weaving amplitude, $\alpha$ is the inclination angle. In our welding experiment, the inclination angle $\alpha$ keeps constant, and the 
weaving track is determined as the triangular weaving. Once the welding consumable is selected, the density of the droplet is constant, the droplet mass mainly depends on the droplet size. In addition, a larger weaving amplitude leads to a larger inertial force under the condition of constant weaving frequency. Similarity, a larger weaving frequency also leads to a larger inertial force under the condition of constant weaving amplitude.

According to the State-Force-Balance-Theory (SFBT), it postulates that the droplet detachment occurs when the detaching force promoting the droplet transfer exceed the retaining forces [17]. To better understand the droplet transfer behavior in vertical-up weaving welding, it is necessary to analyse the different forces acting on a pendant droplet. In particular, the electromagnetic force and the weaving inertial force are the main forces in governing the formation and detachment of the droplet. Based on the prior analysis, the magnitude and direction of the electromagnetic force has close relation with the arc shape (Fig. 21) and the weaving inertial force is associated with the weaving frequency and amplitude. Therefore, the arc shape, weaving frequency and weaving amplitude play a dominant role in determining the magnitude and direction of the forces acting on the droplet during the vertical weaving welding.

\subsection{Stability control of droplet transfer}

As noted previously that the incomplete root penetration and lack of sidewall fusion are two kinds of the most common defects in the vertical-up weaving welding on thick plate. Based on the prior analysis, the fusion states of the root and sidewall mainly depend on the droplet transfer behavior under various welding conditions. Additionally, the stability of droplet transfer mainly relates to the droplet transfer frequency, average diameter of the droplet, impacting location of the droplet and the transfer mode. As a consequence, how to better control the stability of droplet transfer and mitigate the occurrence of the defects is much essential for ensuring a sound weld appearance and high-quality weld.

\subsubsection{Analysis of weaving arc characteristic}

As discussed above, the knowledge of correlation of with the arc characteristics and behaviour of droplet transfer is of importance to understand the mechanism of the droplet transfer. In this regard, we performed a comparison analysis on the arc characteristics and droplet transfer in vertical welding with and without weaving mode, which as shown in Fig. 22.

(1) Without weaving mode, due to the combined effect of the gravity, electromagnetic force, surface tension and plasma drag force, the detached droplets fly out to the front-side of the molten pool, as shown Fig. 22(a). Considering the heat carried by the droplet is much less than the arc heat, it only can melt a small amount of metal, which will generate a pear-shaped molten pool with a shallower front-side and wider rear-side. Moreover, with a larger temperature gradient at the front-side of the molten pool, the droplets impacting on the molten pool will cool rapidly, which could change the front-side of the liquid molten pool into a solid form, and further cause the defect of the incomplete root penetration.

(2) Compared with the arc shape without weaving mode, the arc column region becomes smaller with a shrinking and symmetric arc in weaving mode, thus the direction of resultant force acting on the droplet points to the center of the molten pool, which as shown in Fig.22(b). Moreover, except for the gravity, electromagnetic force, surface tension and plasma flow force, the weaving inertial force is also an important force acting on the droplet in the weaving welding. Under the common effect of these forces above, the droplets could steadily transfer into the molten pool. Consequently, the degree of arc constriction mainly affects the distribution of the 
actual forces and the impacting location of the droplet, which further determining the fusion state of groove root.
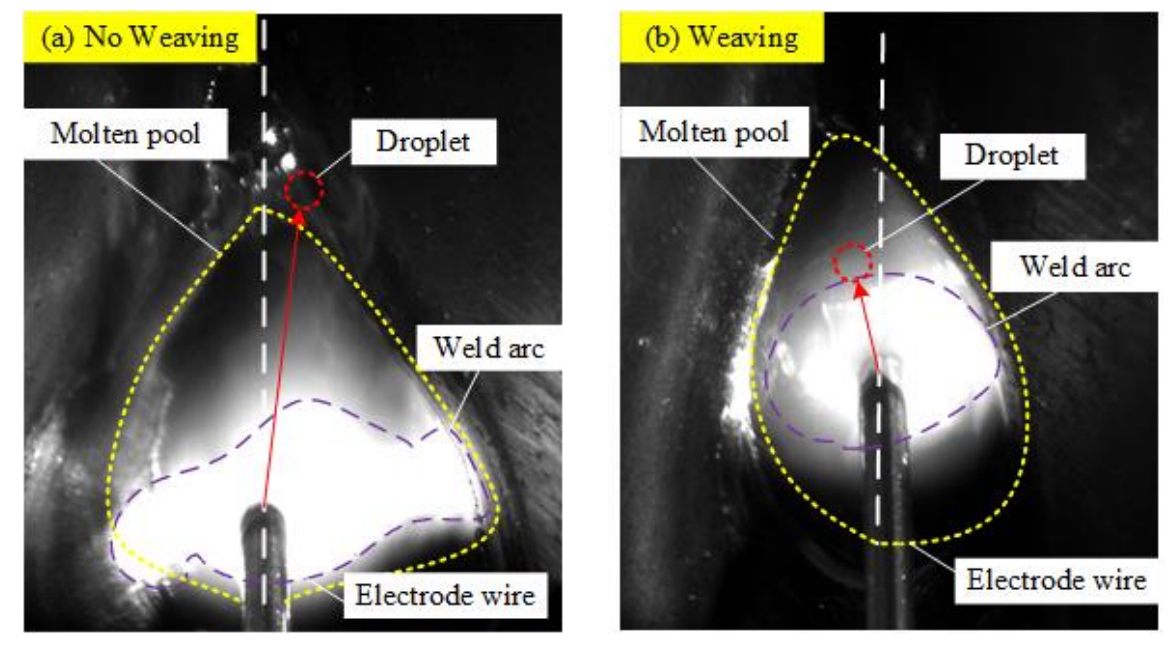

Fig. 22. Arc shape and molten pool in vertical-up welding with (a) no weaving and weaving.

\subsubsection{Impacting location control of the droplet}

As explained earlier, the defects of the incomplete root penetration and lack of sidewall fusion easily occur in the vertical weaving welding on thick plate. To further understand the cause of these welding defects and then reduce the creation of defects, we acquired a series of images of the droplet transfer process with different weaving parameters by applying the high-speed image acquisition system The welding experiments results indicate that a larger weaving amplitude and dwell-time could solve the problem of the sidewall fusion well, however, it also affects the stability of the droplet transfer and further increases the tendency for forming the welding defects. Fig. 23 presents the droplet transfer process with the weaving amplitude of $2.5 \mathrm{~mm}$ (No.6) and the dwell time of 1.0s (No.9), respectively, we can see that the two different welding parameters can obtain a fully complete sidewall fusion. However, the impacting location of the droplets are both in the front-side of the "pear-shaped" molten pool, and the incomplete root penetration easily exists in the welding joint, thereby further reducing the vertical weaving weld quality. Therefore, it is essential to control the impacting location of the droplet on the molten pool for avoiding the incomplete root penetration.
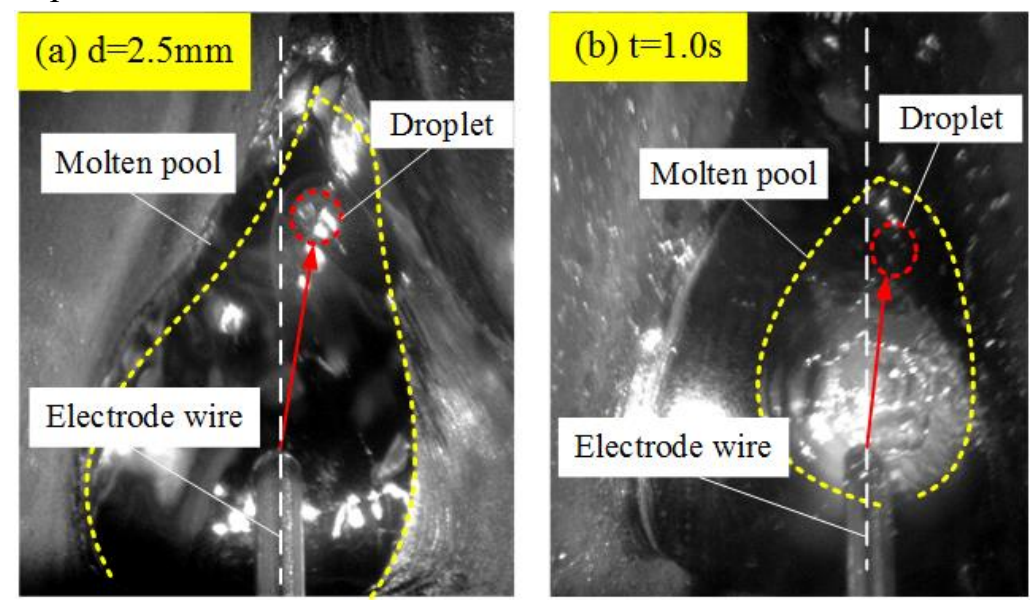

Fig. 23. Droplet transfer in arc welding with weaving on groove sidewall (a) $\mathrm{d}=2.5 \mathrm{~mm}$ (b) $\mathrm{t}=1.0 \mathrm{~s}$.

Based on our prior analysis, the key factor in determining the root penetration is the impacting location of the droplet, which is determined by the forces acting on the droplet. For the 
specific workpiece, the selection of the weaving amplitude depends mostly on the size and shape of the workpiece, however, the adjusting range of the weaving amplitude is limited. Moreover, the dwell time on the sidewall mainly affects the fusion state of the sidewall instead of groove root. Thus, the weaving frequency is the main factor in affecting the force acting on the droplet. In this study, we can adjust the weaving frequency to change the actual arc shape, in order to change the the magnitude and direction of the electromagnetic force. Meantime, the weaving inertial force $\left(F_{i}\right)$ will also change with the variation of the weaving frequency.

To demonstrate the effect of the weaving frequency on the locations where the droplets impinge on the molten pool, Fig. 24 describes the forces acting on the droplet with different weaving frequency $(1.2 \mathrm{~Hz}$ and $1.8 \mathrm{~Hz})$, and the weaving amplitude and dwell time on the sidewalls are $1.5 \mathrm{~mm}$ and $0.5 \mathrm{~s}$, respectively. As shown in figure, when the weaving frequency becomes larger at $1.8 . \mathrm{Hz}$, the arc shape will change from the constriction state to expansion state, which will make the direction of the electromagnetic force point to the front-side of the electrode wire. Moreover, the balance of the electromagnetic force and the weaving inertial force could better control the impact location of the droplet. In conclusion, the incomplete sidewall fusion can be suppressed by adjusting the weaving amplitude and dwell-time with the constant welding parameters. The forces acting on droplet can be changed by adjusting weaving frequency to achieve a stable droplet transfer and avoid the incomplete root penetration of thick plate.

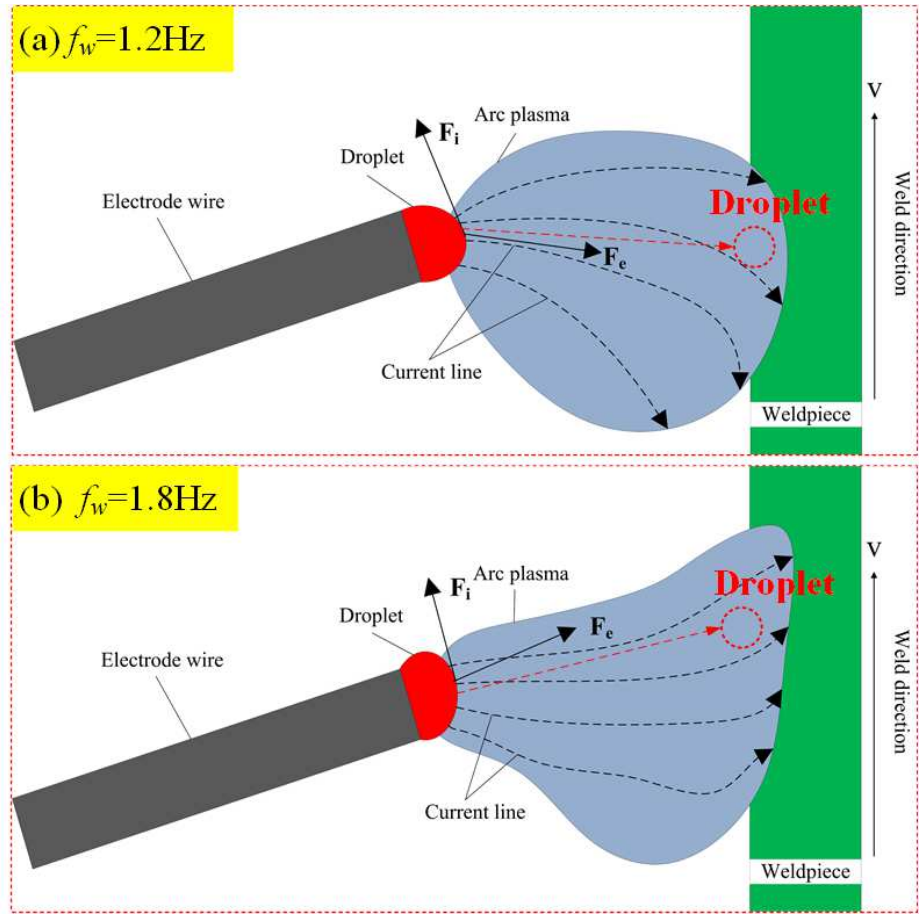

Fig. 24. Forces acting on droplet under different weaving frequency (a) $f_{w}=1.2 \mathrm{~Hz}$ (b) $f_{w}=1.8 \mathrm{~Hz}$. 


\section{Conclusions}

With the synchronous observation of high-speed photography and current/voltage signals, our research investigated the arc characteristics and droplet transfer behavior of the weaving vertical-up P-GMAW on thick plate, which aims to provide an insight into how to control the droplet transfer stability and improve the weld quality. The investigation leads to the following conclusions:

1) By using the statistical analysis, the average diameter, impact location and transfer frequency of the droplet can characterize the dynamic behavior of the droplet transfer in P-GMAW quantitatively;

2) Compared to the welding without weaving, arc weaving motion with angle $\left(85^{\circ}\right)$ can easily facilitate the droplet detach from the electrode tip without large spatters and improve the stability of droplet transfer;

3) The incomplete sidewall fusion can be effectively suppressed by adjusting the weaving amplitude $(1.5 \mathrm{~mm})$ and dwell-time (1.0s) with enough weaving-arc heat input. The forces acting on droplet can be changed by adjusting weaving frequency $(1.2 \mathrm{~Hz})$ to make the droplet steadily transfer into the molten pool and avoid the incomplete root penetration;

4) The novel weaving-force model incorporating the weaving inertial force is established to understand the drop transfer mechanism and explain the influences of the weaving parameters on the dynamic characteristics and stability control of the droplet transfer.

Author's contributions All authors contributed equally to this work.

Funding This work was supported in part by the China Postdoctoral Science Foundation under Grant 2021M692039, in part by the National Science Foundation of China under Grant 51905333 and 52075317, and in part by Shanghai Sailing Plan under Grant 19YF1418100.

\section{Declarations}

Competing interests The authors declare that they have no conflict of interest.

Consent to participate Consent.

Consent to publish Consent.

\section{References}

[1] D. Schroepfer, T. Kannengiesser, Stress build-up in HSLA steel welds due to material behaviour, J Mater Process Technol. 227 (2016) 49-58.

[2] H. Fan, R. Kovacevic, Droplet formation, detachment, and impingement on the molten pool in gas metal arc welding. Metall Mater Trans B. 30(4) (1999) 791-801.

[3] X. Zhang, H. Gao, G. Zhang, Current-independent metal transfer by utilizing droplet resonance in gas metal arc welding, J Mater Process Technol. 279 (2020), 116571.

[4] P. Kah, R. Suoranta, J. Martikainen, Advanced gas metal arc welding processes, Int J Adv Manuf Technol, 67(1) (2013), 655-674. 
[5] P. Ghosh, L. Dorn, M. Hübner, V. Goyal, Arc characteristics and behaviour of metal transfer in pulsed current GMA welding of aluminium alloy, J Mater Process Technol. 194(1-3) (2007) 163-175.

[6] P. Ghosh, S. Kulkarni, M. Kumar, H. Dhiman, Pulsed current GMAW for superior weld quality of austenitic stainless steel sheet, ISIJ international. 47(1) (2007) 138-145.

[7] A. Joseph, D. Farson, D. Harwig, R. Richardson, Inflfluence of P-GMAW current waveforms on heat input and weld bead shape, Sci Technol Weld Join, 10(2005) 311-318.

[8] S. Subramaniam, D. White, J. Jones, D. Lyons, Droplet transfer in pulsed gas metal arc welding of aluminum, Weld J. 77 (1998) 458-s.

[9] H. De Miranda, A. Scotti, V. Ferraresi, Identification and control of metal transfer in pulsed GMAW using optical sensor, Sci Technol Weld Join. 12(3) (2007) 249-257.

[10] P. Ghosh, L. Dorn, S. Kulkarni, F. Hofmann, Arc characteristics and behaviour of metal transfer in pulsed current GMA welding of stainless steel, J Mater Process Technol. 209(3) (2009) 1262-1274.

[11] K. Wu, X. Cao, T. Yin, M. Zeng, Z. Liang, Metal transfer process and properties of double-wire double pulsed gas metal arc welding, J Manuf Process. 44 (2019) 367-375.

[12] Y. Chen, J. Feng, L. Li, Y. Li, S. Chang, Effects of welding positions on droplet transfer in CO 2 laser - MAG hybrid welding. Int J Adv Manuf Technol, 68(5-8) (2013), 1351-1359.

[13] X. Cai, X., Lin, S., Cheng, Y., Yang, D., Yang, C., \& Fan, C. (2019). The effects of double groove type on the backing weld penetration in swing arc vertical-up MAG welding. Welding in the World, 63(4), 1133-1143.

[14] Y. Chen, C. Yang, H. Chen, H. Zhang, S. Chen, Microstructure and mechanical properties of HSLA thick plates welded by novel double-sided gas metal arc welding, Int J Adv Manuf Technol. 78(1-4) (2015) 457-464.

[15] Y. Li, C. Wu, L. Wang, J. Gao, Analysis of additional electromagnetic force for mitigating the humping bead in high-speed gas metal arc welding, J Mater Process Technol. 229 (2016) 207-215.

[16] Y. Kim, T. Eagar, Analysis of metal transfer in gas metal arc welding. Weld J., 72 (1993) 269-278.

[17] Y. Kim, T. Eagar, Metal transfer in pulsed current gas metal arc welding. Weld J., 72(7) (1993), 279-287. 